\title{
PULL-OUT BEHAVIOUR OF GLASS-FIBRE REINFORCED POLYMER PERFORATED PLATE CONNECTORS EMBEDDED IN CONCRETE. PART I: EXPERIMENTAL PROGRAM
}

\author{
Rodrigo Lameiras*1, Isabel B. Valente ${ }^{2}$, Joaquim A. O. Barros ${ }^{2}$, Miguel Azenha², Cláudia Gonçalves ${ }^{3}$ \\ ${ }^{1}$ University of Brasília. Department of Civil and Environmental Engineering, Faculty of Technology. Campus \\ Darcy Ribeiro, 70910-900, Brasília, Brazil. Tel: +55 61 31075502; E-mail address: rmlameiras@gmail.com. \\ ${ }^{2}$ ISISE, Universidade do Minho, Campus de Azurém. 4800-058. Guimarães, Portugal. \\ ${ }^{3}$ Domingos da Silva Teixeira SA. 4711-911. Braga, Portugal.
}

\begin{abstract}
The Glass Fibre Reinforced Polymer (GFRP) connectors studied in this work were previously proposed by the authors for connecting the outer Steel Fibre Reinforced Self-Compacting Concrete (SFRSCC) layers of sandwich panels for prefabricated modular housing. In this building system, SFRSCC was used to totally eliminate the need for conventional reinforcement and to decrease the thickness of the panel's outer layers, with consequent reduction of the global self-weigh of the panels, while GFRP connectors aimed to significantly decrease thermal bridging effects. For a reliable design of the structural elements that make use of these connectors, the mechanical behaviour of this connection should be known and taken into account. The present paper summarizes the results obtained in an experimental research devoted to the assessment of the behaviour of GFRP-SFRSCC connection by performing pullout tests with specimens representative of the developed sandwich panel. The specimens were designed to examine the influence of the number and geometry of holes executed in the GFRP connector that assure the connection between these two materials.
\end{abstract}

KEYWORDS: Glass Fibre Reinforced Polymer (GFRP), Steel Fibre Reinforced Self-Compacting Concrete (SFRSCC), Connectors, Composite Structures, Pull-out test, PERFOFRP.

*- corresponding author. 


\section{INTRODUCTION}

In the technology of precast concrete sandwich panels, composite action between the two outer concrete layers is most usually provided by shear connectors [1-8]. In a previous work the authors of the present paper proposed an innovative solution for precast sandwich panels comprising outer layers made with Steel Fibre Reinforced SelfCompacting Concrete (SFRSCC) and connectors of Glass Fibre Reinforced Polymer (GFRP) [9, 10]. These panels consist on two outer concrete layers, a thermal insulation material in the core, and GFRP connectors that are used to tie the SFRSCC layers together and keep the panel intact during the stripping, transporting, erecting and under service conditions (Figure 1). Based on the results of numerical analyses of panels under ultimate limit state, Lameiras et al. [10] suggested that, for housing façade panels, the SFRSCC layers could be as thin as $30 \mathrm{~mm}$. Considering that for economic and practical purposes there is a strong interest of the constructor on keeping the thickness of the sandwich panel concrete layers as small as possible, and also taking into account the constraints for assuring proper embedment conditions for the connector, the authors indicated a thickness of $60 \mathrm{~mm}$ for the thickness of the SFRSCC layer. In these previous studies, different solutions to connect the SFRSCC outer layers were also investigated, and their effectiveness was compared by executing preliminary pull-out tests. Amongst the investigated alternatives, the ones that consisted on perforated GFRP plates (hereafter called PERFOFRP) presented a remarkable performance during the preliminary pull-out tests [9].

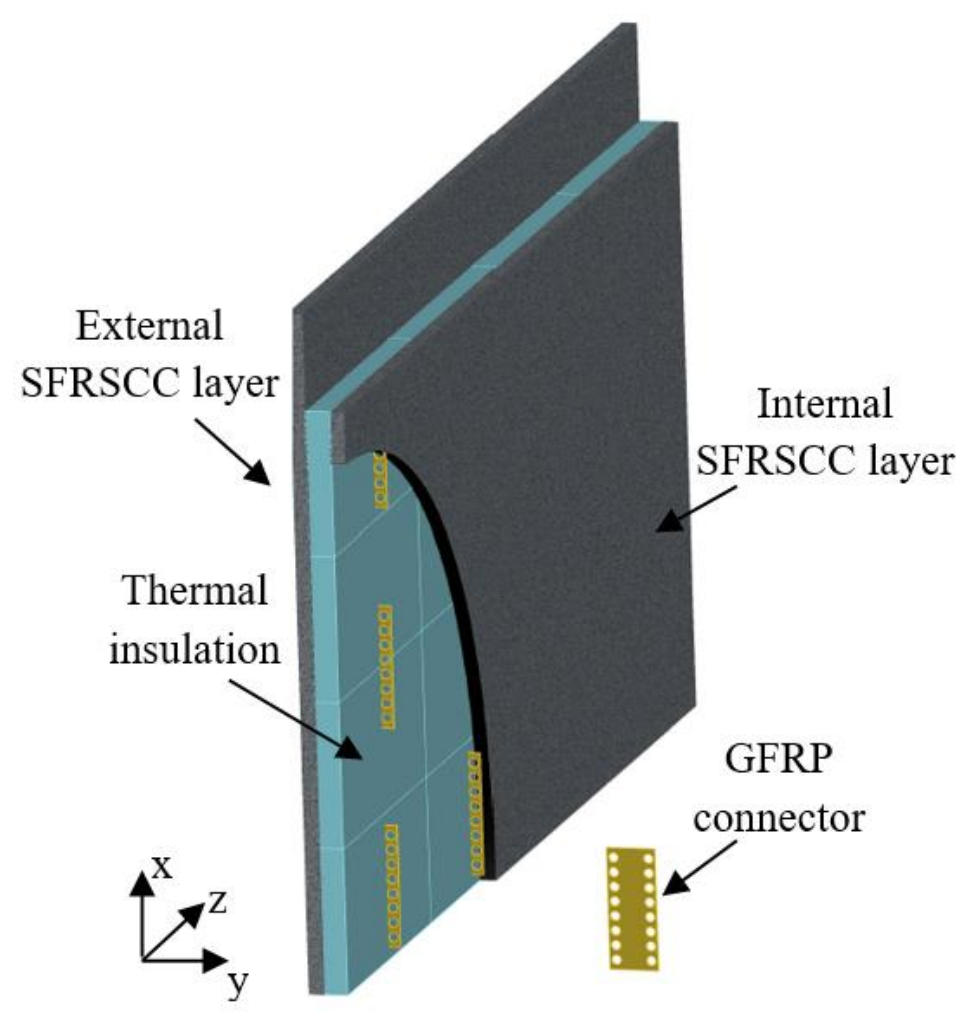

Figure 1: Sandwich panel comprising GFRP connectors. 
The development of the PERFOFRP connector was inspired on the steel Perfobond rib shear connector, but taking advantage of the inherent properties of the GFRP (i.e., reduced thermal conductivity and immunity to corrosion). The steel Perfobond technology was originally developed for railway bridges [11], and since then several studies have been carried out to check its applicability in composite floor systems [12-18]. More recently Cho et al. [19] proposed perforated shear connectors in Fibre Reinforced Polymer (FRP) for a FRP-concrete composite deck. The connector investigated herein has similarities with the proposal by Cho et al. [19], with the main differences between them being related to the restraint imposed by the quite limited embedment depth available for the connectors in the sandwich panels (i.e., concrete cover and geometry of the connector).

The performance of the composite panel is highly influenced by the mechanical behaviour of these connections in the longitudinal and transversal directions of the panel. The longitudinal stiffness of the shear connection affects the flexural rigidity of the composite section and defines its degree of composite action. In fact, the full composite action is practically attained when the longitudinal stiffness is high and, consequently, the corresponding transversal deflections in the sandwich panel are smaller. Therefore, the longitudinal stiffness of the connection should be considered in the evaluation of the serviceability requirements (i.e., deflection limits) when the connectors longitudinal stiffness is low. In addition, the longitudinal strength of these connections is especially important to the case of precast panels that are generally transported in the vertical position, as shown in Figure 2a, since the panels are generally transported by suspending one of the layers, therefore the deadweight of the other layer is transferred through the connectors. On the other hand, the transversal behaviour is related to how the connection resists the forces that tend to separate both concrete layers. Such type of transversal tensile stresses arises mainly during stripping and erection operations of panels (Figure 2b). The magnitude of these tensile stresses is difficult to estimate due to dynamic effects that are involved during these operations. During the panels service life, these connections also experience continuous variation of transversal tensile stress due to thermal cycles and wind action. Thus, the panel should have a performance in the transversal direction that assures the required resisting tensile capacity.

Numerous studies have been devoted to the parametric study of steel Perfobond connectors based on tests and numerical simulations [20, 21]. Moreover, formulations have been proposed to estimate the shear strength of this type of connection [18, 20, 22-24]. 

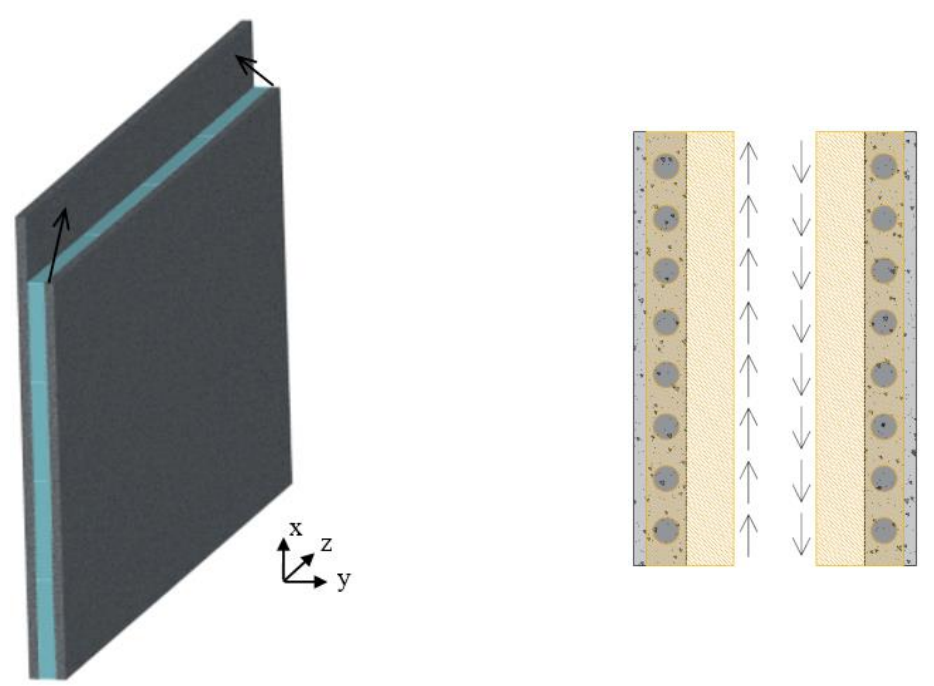

a)
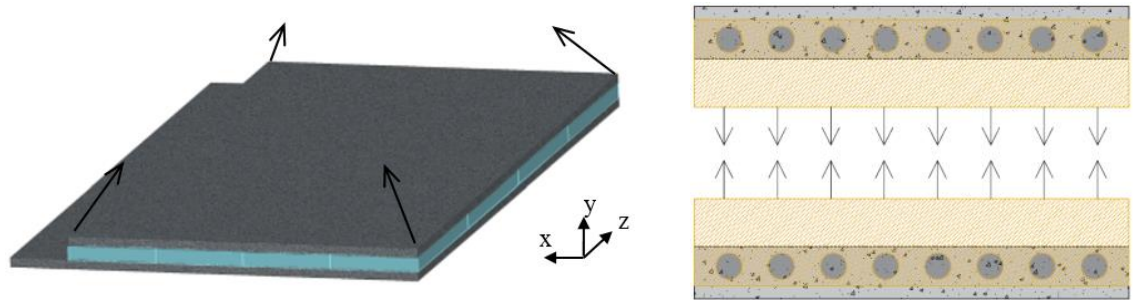

b)

Figure 2: Bearing loads acting on the connectors: a) longitudinal shear (e.g.;

during transporting); b) transversal shear (e.g.; during stripping and transporting).

The geometry of the PERFOFRP connector is similar to the Perfobond connector, but the overall design and mechanical behaviour of this connection differs from the steel Perfobond due to the lower strength and elastic modulus of GFRP comparatively to steel. According to tests carried out by Lameiras et al. [9], the main concern of connections made with PERFOFRP connectors is their shear failure. It is expected, therefore, that in addition to the failure modes resulting from the rupture of the concrete itself (Figure $3 \mathrm{a}, \mathrm{b}$ and $\mathrm{c}$ ), the possible failure modes of the PERFOFRP connector must be also considered (Figure 3d, Figure 3e and f).
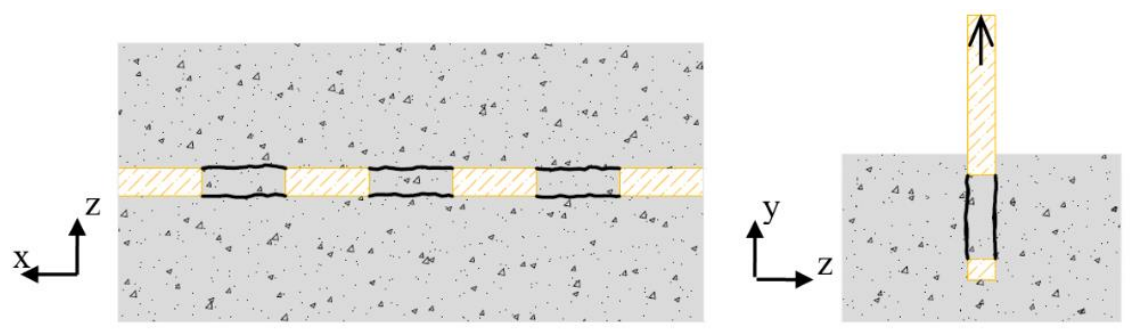

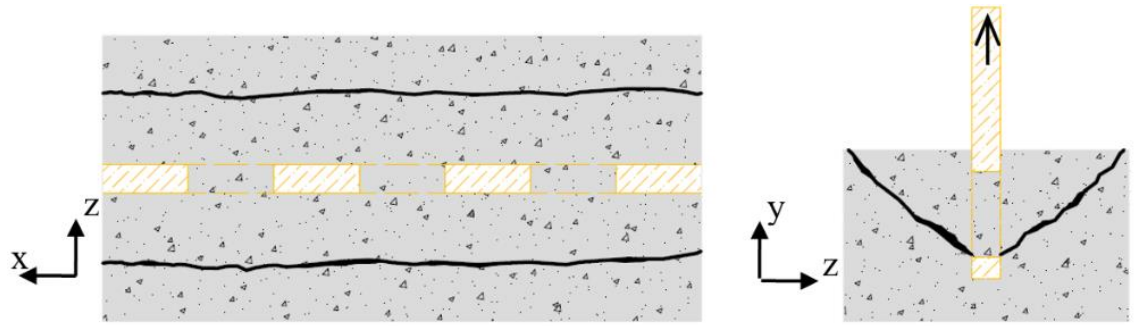

b)

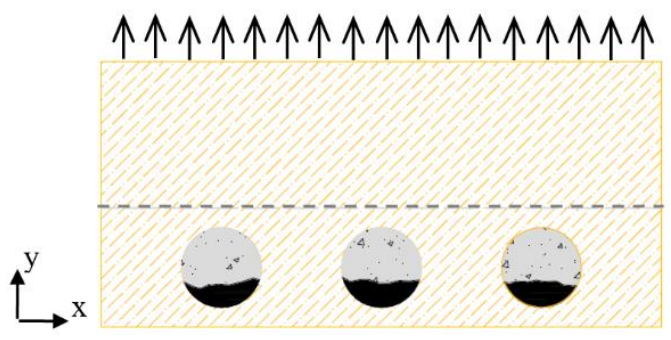

c)

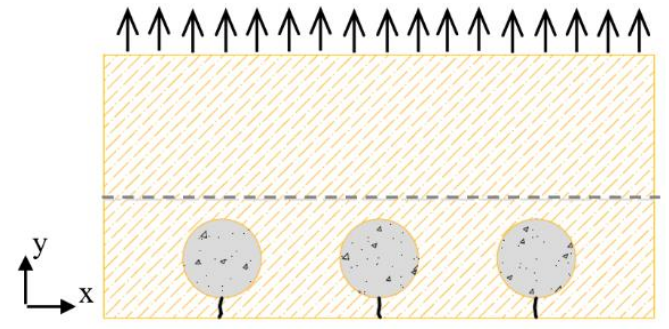

d)

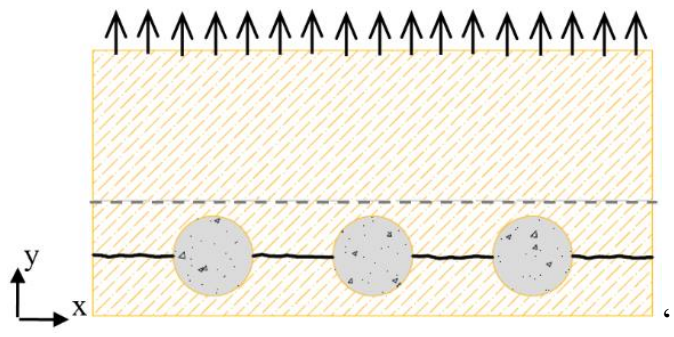

e)

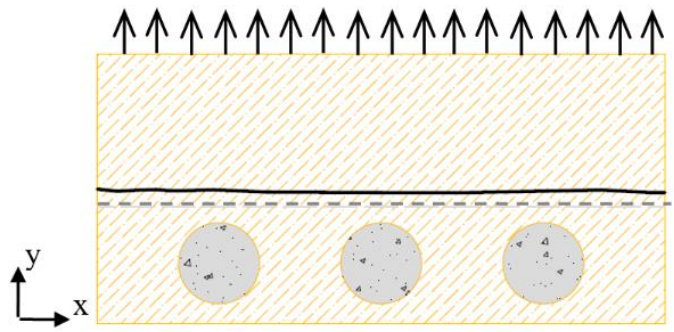

f)

Figure 3: Failure mechanisms likely to occur when the connections are subjected to transversal shear. On SFRSCC: a) shear of the SFRSCC dowels; b) concrete cone rupture and c) crushing. On GFRP connector: d) rupture of the GFRP below the SFRSCC dowels; e) rupture of the GFRP between the SFRSCC dowels and f) 
rupture of the GFRP on the free section.

The present paper aims to deeply investigate the behaviour of the PERFOFRP connectors when subjected to tensile stresses. For this purpose, pull-out tests were conducted with PERFOFRP connectors by using specimen and loading configurations capable of reproducing, as much as possible, the conditions found in a sandwich panel.

The variables investigated included the type of GFRP, the number of holes of connector, and the type of concrete (conventional and fiber reinforced self-compacting concrete). The contributions of the resisting mechanisms (i.e., SFRSCC dowel effect and frictional resistance, schematically represented in Figure 4) were evaluated by comparing the results of tests on connectors with and without holes.

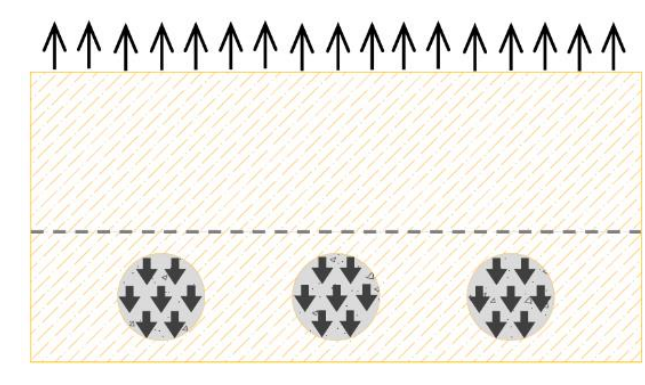

a)

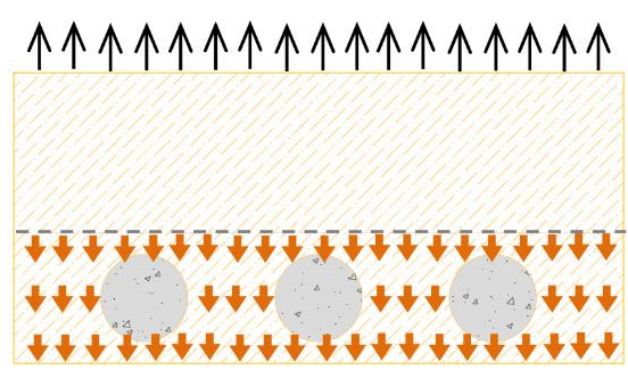

b)

Figure 4: Main load transfer mechanisms acting on the connectors due to loads applied transversally to the concrete layer: a) SFRSCC dowel effect (including the fibre reinforcement mechanisms); b) friction/adherence resistance between GFRP and SFRSCC.

\section{EXPERIMENTAL PROGRAM}

The experimental program, carried out at the Laboratory of the Structural Division of the University of Minho, included a total of 24 pull-out tests on GFRP connectors embedded in bulk concrete blocks. 


\subsection{Material Properties}

\subsubsection{GFRP laminate}

All the composites used in this research consisted of polyester resin matrix and E-glass fibre reinforcement. The polyester resin used to prepare the composites is characterized by the following cured properties given by the manufacturer [25]: $45 \mathrm{MPa}$ for the tensile strength, $3100 \mathrm{MPa}$ for the tensile modulus and $1.6 \%$ for the elongation at break.

Four types of GFRP were used: 1) CSM; 2) BIA; 3) MU2 and 4) MU4. The first laminate was made of a Chopped Strand Mat (CSM) reinforcement. This solution had already demonstrated satisfactory behaviour when employed as a constituent material for connectors [9]. The CSM composite comprised short length fibres randomly oriented in its plane, as shown in Figure 5a. The laminate was obtained by stacking 5 mat layers of $450 \mathrm{~g} / \mathrm{m}^{2}$ each, resulting $2250 \mathrm{~g} / \mathrm{m}^{2}$ of glass fibre reinforcement. Its final thickness is about $2.0 \mathrm{~mm}$, and a fibre content by volume of $41 \%$, determined by the resin burn-off method ASTM D2584 [26].

CSM

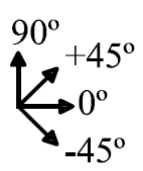

Fibre content

per direction

$\left[\mathrm{g} / \mathrm{m}^{2}\right]:$

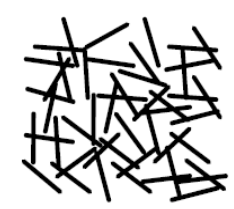

CSM: 2250

(a)
BIA

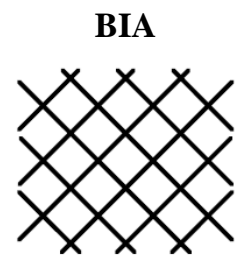

$+45^{\circ}: 1600$

$-45^{\circ}: 1600$

(b)
MU2

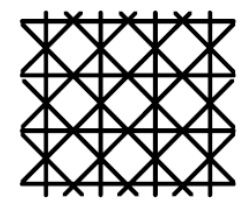

$0^{\circ}: 300$

$90^{\circ}: 300$

$+45^{\circ}: 1200$

$-45^{\circ}: 1200$

(c)
MU4

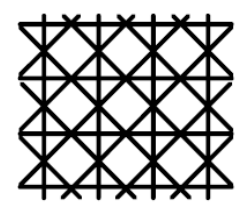

0: 590

$90^{\circ}: 610$

$+45^{\circ}: 2400$

$-45^{\circ}: 2400$

(d)

Figure 5: Schematic representation of used materials: (a) CSM; (b) BIA; (c) MU2; (d) MU4.

The BIA laminate comprised long fibres arranged on $\pm 45^{\circ}$ directions (see a schematic representation of the material in Figure 5b). The reinforcement used in this solution was supplied in bi-axial Stitched Roving Fabrics (SRF) containing 8 mat layers of $400 \mathrm{~g} / \mathrm{m}^{2}$ each. It is characterized by an average thickness of $2.2 \mathrm{~mm}$, and a fibre content by volume of $51 \%$. Considering that in simply supported panels subjected to transversal loading the maximum shear stress planes occur at $45^{\circ}$ to the longitudinal direction, the BIA laminate may be the most effective one to transmit the shear forces that occur in the sandwich panel. However, the absence of fibres at $0^{\circ}$ and $90^{\circ}$ can lead to unsatisfactory behaviour of the connection, resulting in premature failures localized on the proximity of holes.

The third and fourth laminates were produced using the same manufacturing process, the same constituent materials and the same fibre volumetric proportion. They differed only on the number of layers and, consequently, on the total 
thickness of the laminates. The laminate of the third material alternative (MU2) was obtained by stacking 6 layers of $400 \mathrm{~g} / \mathrm{m}^{2} \pm 45^{\circ}$ stitched-bonded mats and one layer of $0^{\circ} / 90^{\circ}$ containing $300 \mathrm{~g} / \mathrm{m}^{2}$ in each direction, positioned in the symmetry plane (see Figure 5c). On the other hand, the fourth material alternative (MU4) included 12 layers of $400 \mathrm{~g} / \mathrm{m}^{2} \pm 45^{\circ}$ stitched-bonded mats and one layer of $0^{\circ} / 90^{\circ}$ containing approximately $600 \mathrm{~g} / \mathrm{m}^{2}$ in each direction (see Figure 5d). The average total thicknesses of third and fourth laminates is, respectively, $2.2 \mathrm{~mm}$ and $4.0 \mathrm{~mm}$. The fibre volume fraction of these laminates is $49 \%$.

All the materials were produced in the installations of Pole for Innovation in Polymer Engineering (PIEP). The manufacture process adopted is the Vacuum Assisted Resin Transfer Moulding (VARTM). Details about the composite layup and the thickness of laminates are grouped in Table 8 and the total amount of fibres per direction is given in Table 9.

Table 1: Composites lay-ups and thicknesses.

\begin{tabular}{|c|c|c|c|}
\hline \multirow[b]{2}{*}{ Laminate } & \multicolumn{2}{|c|}{ Stacking sequence } & \multirow{2}{*}{$\begin{array}{c}\text { Thickness } \\
\text { [mm] }\end{array}$} \\
\hline & $\begin{array}{l}\text { N. of } \\
\text { layers }\end{array}$ & $\begin{array}{l}\text { Material of each } \\
\text { layer* }\end{array}$ & \\
\hline CSM & 5 & $\mathrm{CSM} / 450$ & 2.0 \\
\hline BIA & 8 & SRF/+45-45/400 & 2.2 \\
\hline \multirow{3}{*}{ MU2 } & 3 & SRF/+45-45/400 & \multirow{3}{*}{2.2} \\
\hline & 1 & SRF/090/300 & \\
\hline & 3 & $\mathrm{SRF} /+45-45 / 400$ & \\
\hline \multirow{3}{*}{ MU4 } & 6 & SRF/+45-45/400 & \multirow{3}{*}{4.0} \\
\hline & 1 & SRF/090/600 & \\
\hline & 6 & $\mathrm{SRF} /+45-45 / 400$ & \\
\hline
\end{tabular}

* - CSM/450: CSM with $450 \mathrm{~g} / \mathrm{m} 2$ of E-glass fibres randomly distributed; SRF/+45-45/400: stitched roving fabric with $400 \mathrm{~g} / \mathrm{m} 2$ of E-glass fibres in the directions $\pm 45^{\circ} ; \mathrm{SRF} / 090 / 300$ : stitched roving fabric with $300 \mathrm{~g} / \mathrm{m} 2$ of E-glass fibres in the directions $0^{\circ}$ and $90^{\circ}$; SRF/090/600: stitched roving fabric with $600 \mathrm{~g} / \mathrm{m} 2$ of E-glass fibres in the directions $0^{\circ}$ and $90^{\circ}$.

Table 2: Total amount of glass fibre per composite.

\begin{tabular}{ccccccc}
\hline & \multicolumn{5}{c}{ Content of glass fibre $\left[\mathrm{g} / \mathrm{m}^{2}\right]$} \\
\cline { 2 - 6 } Laminate & \multicolumn{6}{c}{ Per direction } \\
\cline { 2 - 6 } & Randomly & $0^{\circ}$ & $90^{\circ}$ & $-45^{\circ}$ & $45^{\circ}$ & \\
\hline CSM & 2250 & 0 & 0 & 0 & 0 & 2250 \\
\hline BIA & 0 & 0 & 0 & 1600 & 1600 & 3200 \\
\hline MU2 & 0 & 300 & 300 & 1200 & 1200 & 3000 \\
\hline MU4 & 0 & 590 & 610 & 2400 & 2400 & 6000 \\
\hline
\end{tabular}

Direct tensile tests under constant head-speed rate of $2 \mathrm{~mm} / \mathrm{min}$ were executed for the determination of the mechanical properties of the composites. The tests were performed along the $0^{\circ} / 90^{\circ}$ direction $(x-$ or $y$ - axis 
according to the global axis of pull-out tests, Figure 1). The specimens used for the GFRP characterization were extracted from flat plates produced following the same procedures adopted for the fabrication of the connectors. The specimens were $25 \mathrm{~mm}$ wide and $250 \mathrm{~mm}$ long. The test procedures described in ASTM D3039 [27] were followed, and tensile strength, stiffness and stress-strain relationship up to failure were determined. A clip-gauge with reference length of $50 \mathrm{~mm}$, fixed in the middle of each specimen, was used to measure the strain in the longitudinal direction. To provide appropriate anchorage during testing, and to diffuse the clamping stresses, rectangular steel tabs $(50 \mathrm{~mm} \times 25 \mathrm{~mm} \times 1 \mathrm{~mm})$ were bonded at the extremities of the laminate specimens. The tensile stresses of the laminate specimens were calculated for each data point dividing the registered force by the average cross-sectional area of the specimen. Table 10 summarizes the results of the tensile tests for the GFRPs. The direct tensile stressstrain curves for both types of laminate employed in this research are depicted in Figure 6.

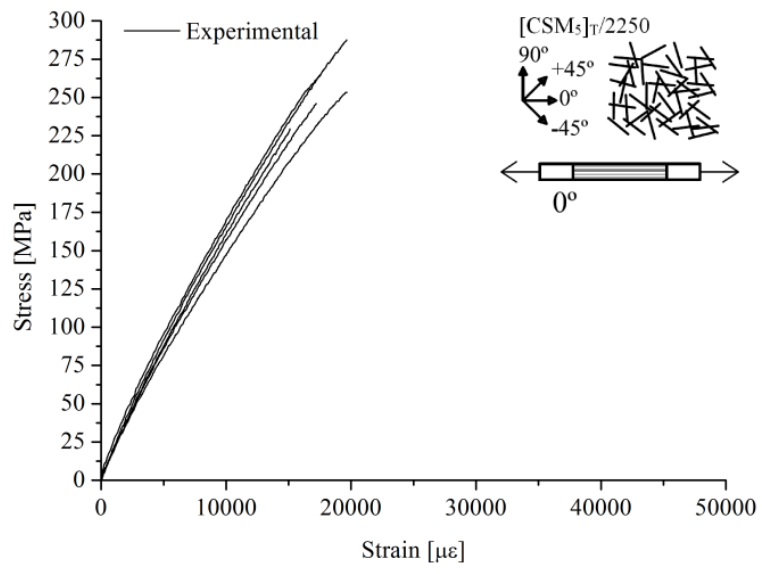

(a)

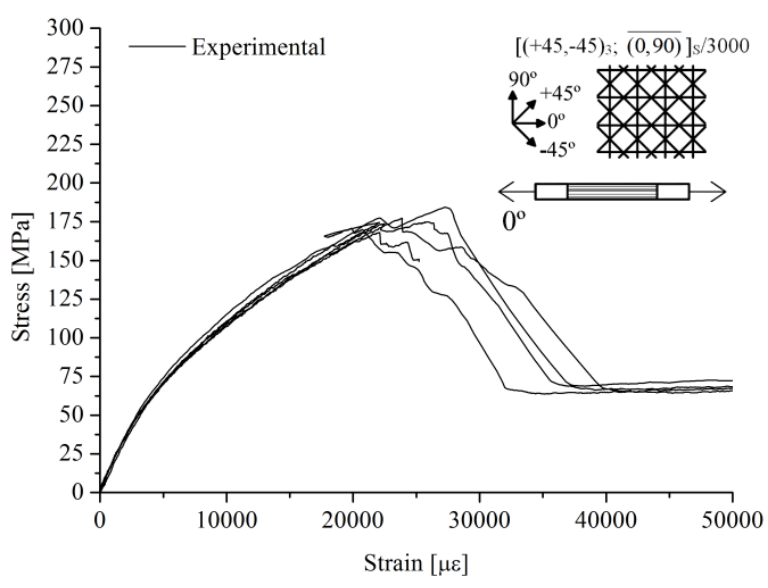

(c)

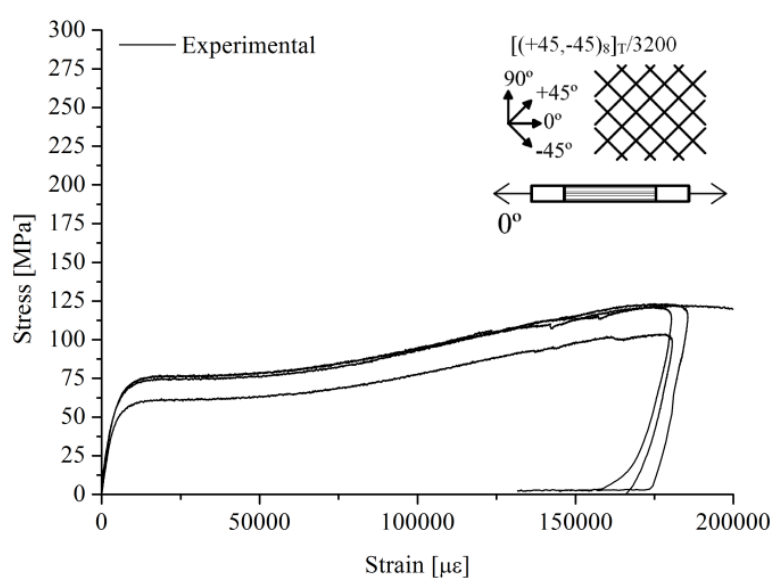

(b)

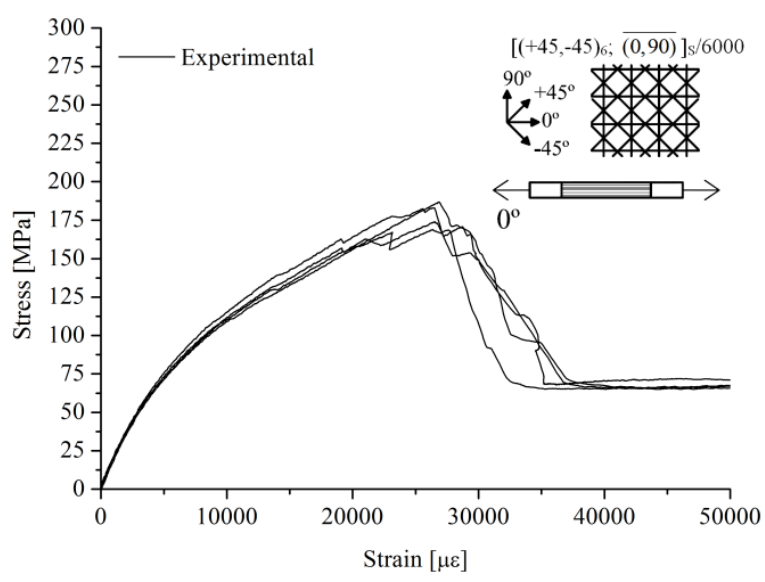

(d)

Figure 6: Experimental stress versus strain relationship for the direct tensile behaviour of the GFRPs in the $0^{\circ}$ direction (along $x$-axis according to the global axis, Figure 2): (a) CSM; (b) BIA; (c) MU2 and (b) MU4. 
Table 3: Ultimate tensile stress $\left(\sigma_{p t . u}\right)$, strain $\left(\varepsilon_{p t . u}\right)$, elastic limit stress $\left(\sigma_{p t . e l}\right)$, strain $\left(\varepsilon_{p t . e l}\right)$ and tensile modulus of elasticity $\left(E_{p t}\right)$ of composites.

\begin{tabular}{|c|c|c|c|c|c|c|c|}
\hline Composite & Dir. & $\begin{array}{l}\text { Sample } \\
\text { size }\end{array}$ & $\begin{array}{c}\text { Ultimate } \\
\text { tensile stress } \\
\sigma_{p t . u} \\
\text { Avg. [MPa] } \\
(\mathrm{CoV})\end{array}$ & $\begin{array}{c}\text { Ultimate } \\
\text { tensile strain } \\
\varepsilon_{p t . u} \\
\text { Avg. }[\mu \varepsilon] \\
(\mathrm{CoV})\end{array}$ & $\begin{array}{c}\text { Elastic limit } \\
\text { stress } \sigma_{\text {p.el }} \\
\text { Avg. }[\mathrm{MPa}] \\
(\mathrm{CoV})\end{array}$ & $\begin{array}{c}\text { Elastic limit } \\
\text { strain } \varepsilon_{p t . e l} \\
\text { Avg. }[\mu \varepsilon] \\
(\mathrm{CoV})\end{array}$ & $\begin{array}{c}\text { Tensile } \\
\text { Modulus of } \\
\text { Elasticity } E_{p t} \\
\text { Avg. }[\mathrm{GPa}] \\
(\mathrm{CoV})\end{array}$ \\
\hline CSM & $0^{\circ} / 90^{\circ}$ & 6 & $\begin{array}{l}252.54 \\
(8.5 \%)\end{array}$ & $\begin{array}{l}18029 \\
(9.8 \%)\end{array}$ & $\begin{array}{l}252.54 \\
(8.5 \%)\end{array}$ & $\begin{array}{l}18029 \\
(9.8 \%)\end{array}$ & $\begin{array}{c}14.64 \\
(7.4 \%)\end{array}$ \\
\hline BIA & $0^{\circ} / 90^{\circ}$ & 6 & $\begin{array}{l}119.59 \\
(3.2 \%)\end{array}$ & $\begin{array}{l}174231 \\
(3.2 \%)\end{array}$ & $\begin{array}{c}71.42 \\
(1.2 \%)\end{array}$ & $\begin{array}{c}9965 \\
(6.3 \%)\end{array}$ & $\begin{array}{c}13.33 \\
(1.4 \%)\end{array}$ \\
\hline MU2 & $0^{\circ} / 90^{\circ}$ & 6 & $\begin{array}{l}175.72 \\
(3.0 \%)\end{array}$ & $\begin{array}{l}24093 \\
(8.5 \%)\end{array}$ & $\begin{array}{c}69.40 \\
(7.1 \%)\end{array}$ & $\begin{array}{c}4788 \\
(9.1 \%)\end{array}$ & $\begin{array}{c}16.23 \\
(2.3 \%)\end{array}$ \\
\hline MU4 & $0^{\circ} / 90^{\circ}$ & 6 & $\begin{array}{l}183.48 \\
(8.5 \%)\end{array}$ & $\begin{array}{l}26788 \\
(2.3 \%)\end{array}$ & $\begin{array}{c}73.44 \\
(4.3 \%)\end{array}$ & $\begin{array}{c}5016 \\
(3.8 \%)\end{array}$ & $\begin{array}{c}16.7 \\
(3.0 \%)\end{array}$ \\
\hline
\end{tabular}

The CSM laminate was also characterized under shear by means of the modified Iosipescu shear test, following the standard procedure described in ASTM D 5379-93 [28]. Values equal to 139.06 MPa and 3.97 GPa were obtained for the ultimate shear stress $\left(\tau_{x y . u l t}\right)$ and the shear modulus of elasticity $\left(G_{x y}\right)$ of CSM laminate, respectively.

For the sake of conciseness, only CSM and MU4 laminates were used to manufacture the PERFOFRP connectors employed in the pull-out tests presented in the first part of this paper. BIA and MU2 laminates were employed together with CSM and MU4 laminates in the pin-bearing tests presented in the second part of this paper [29].

\subsubsection{Concrete}

Pull-out tests were performed with two distinct concrete mixes: (i) SFRSCC; and (ii) Self Compacting Concrete (SCC) without any kind of fiber reinforcement. The use of this second mix was precisely targeted to evaluate the influence of steel fibres embedded in concrete on the mechanical behaviour of the connections. The mix compositions adopted for SCC and SFRSCC are very similar (Table 11), made by the following constituents materials: $\mathrm{C}_{\mathrm{E}}$ - cement, $\mathrm{W}_{\mathrm{A}}$ - water, $\mathrm{S}_{\mathrm{U}}$ - superplasticizer of third generation based on polycarboxylates (SIKA 3005 $\mathrm{HE}), \mathrm{L}_{\mathrm{FI}}$ - limestone filler, $\mathrm{F}_{\mathrm{RS}}$ - fine river sand, $\mathrm{C}_{\mathrm{RS}}$ - coarse river sand, $\mathrm{L}_{\mathrm{CA}}$ - limestone coarse aggregate). The limestone coarse aggregate has a nominal maximum aggregate size equal to $12 \mathrm{~mm}$. The higher water content adopted in the SFRSCC had the purpose of assuring similar slump-flow for both cement composites.

The steel fibres $\left(\mathrm{S}_{\mathrm{FB}}\right)$ employed in the SFRSCC are characterized by a length $\left(L_{f}\right)$ of $35 \mathrm{~mm}$, a diameter $\left(d_{f}\right)$ of $0.55 \mathrm{~mm}$, an aspect ratio $\left(\lambda_{f}=L_{f} / d_{f}\right)$ of 65 , and a yield stress between 1244 and $1446 \mathrm{MPa}$. In the proposed sandwich panels, fibres have the purpose of eliminating the necessity of using conventional steel rebars. For this target, and considering cost competitiveness reasons for the fibre reinforced concrete to be developed, the volume fraction of 
fibres and concrete strength class should be limited. The fibre reinforced concrete mixture has been optimized taking into account the solid experience of some of the co-authors in the technology of fibre reinforced cement composites [30-32]. The fibre reinforced concrete mixture has been optimized to assure pull out failure mode for the fibres, a toughness capable of guaranteeing the required post-cracking tensile capacity for eliminating conventional reinforcement, with rheology requisites for filling perfectly the moulds without occurrence of segregation of the constituents, and with a cost that does not compromise the competitiveness of the proposed solution. If synthetic or micro-steel fibres had been used, the cost of the FRC for attaining identical post-cracking tensile capacity to the one determined in the developed SFRSCC, would be much higher.

The flow spread of concretes in the fresh state was registered by using the inverted Abrams cone and following the recommendations of EFNARC [33]. Average values of flow spread equal to $750 \mathrm{~mm}$ and $770 \mathrm{~mm}$ were obtained for SFRSCC and SCC, respectively. The compressive strength $\left(f_{c m}\right)$ and the elastic modulus $\left(E_{c m}\right)$ of concretes were determined with compressive tests performed on cylinders of $150 \mathrm{~mm}$ diameter and $300 \mathrm{~mm}$ height casted simultaneously with the pull-out specimens. These concrete cylinders were cured for 21 days under laboratory temperature and humidity conditions. The compressive strength was obtained based on the procedures given in EN 12390-3 [34]. The Young's modulus was determined following the procedures described by the Portuguese standard LNEC E397 [35] that are similar to the procedures of international standards, such as RILEM TC 14-CPC [36] and ASTM C469 [37]. At 21 days, the average compressive strength and Young's modulus were, respectively, the following (values in round brackets are the $\mathrm{CoV}): 61.88 \mathrm{MPa}(4.3 \%)$ and $37.02 \mathrm{GPa}(6.5 \%)$ for SFRSCC, and 59.12MPa (3.4\%) and 34.63 GPa (2.7\%) for SCC, measured in 3 and 4 specimens for these respective materials.

Table 4: Compositions of SFRSCC and SCC per $\mathrm{m}^{3}$ of concrete.

\begin{tabular}{ccccccccc}
\hline \multirow{2}{*}{ Material } & $\begin{array}{c}\mathrm{C}_{\mathrm{E}} \\
{[\mathrm{kg}]}\end{array}$ & $\begin{array}{c}\mathrm{W}_{\mathrm{A}} \\
{[\mathrm{kg}]}\end{array}$ & $\begin{array}{c}\mathrm{S}_{\mathrm{U}} \\
{[\mathrm{kg}]}\end{array}$ & $\begin{array}{c}\mathrm{L}_{\mathrm{FI}} \\
{[\mathrm{kg}]}\end{array}$ & $\begin{array}{c}\mathrm{F}_{\mathrm{RS}} \\
{[\mathrm{kg}]}\end{array}$ & $\begin{array}{c}\mathrm{C}_{\mathrm{RS}} \\
{[\mathrm{kg}]}\end{array}$ & $\begin{array}{c}\mathrm{L}_{\mathrm{CA}} \\
{[\mathrm{kg}]}\end{array}$ & $\begin{array}{c}\mathrm{S}_{\mathrm{FB}} \\
{[\mathrm{kg}]}\end{array}$ \\
\hline SFRSCC & 413 & 125 & 7.83 & 353 & 179 & 655 & 588 & 60 \\
SCC & 413 & 116 & 7.83 & 353 & 179 & 655 & 588 & 0 \\
\hline
\end{tabular}

\section{$2.2 \quad$ Specimens}

The geometry and details of pull-out specimens are shown in Figure 7. All the specimens were made of a concrete block (i.e.: SFRSCC or SCC) and a GFRP connector embedded in its centre. The concrete block had an overall thickness of $100 \mathrm{~mm}$ and $400 \mathrm{~mm} \times 246 \mathrm{~mm}$ of plan dimensions. 


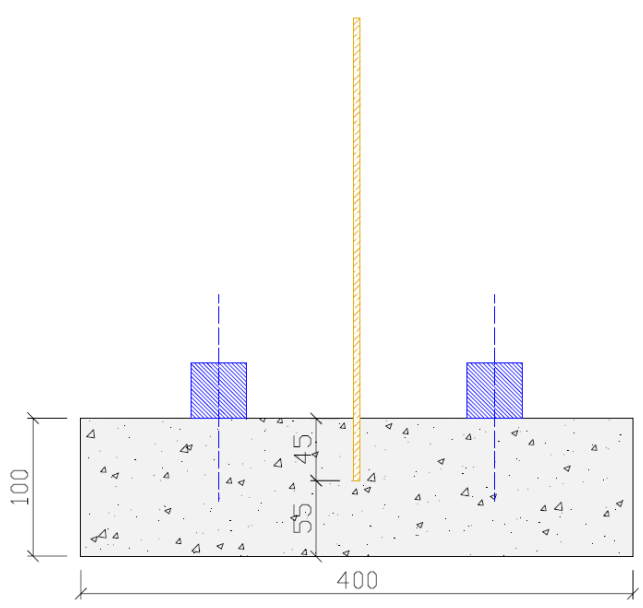

(a)

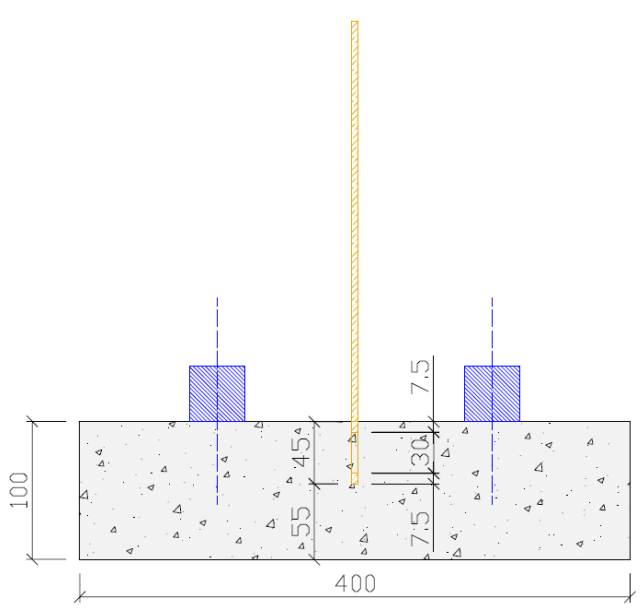

(c)

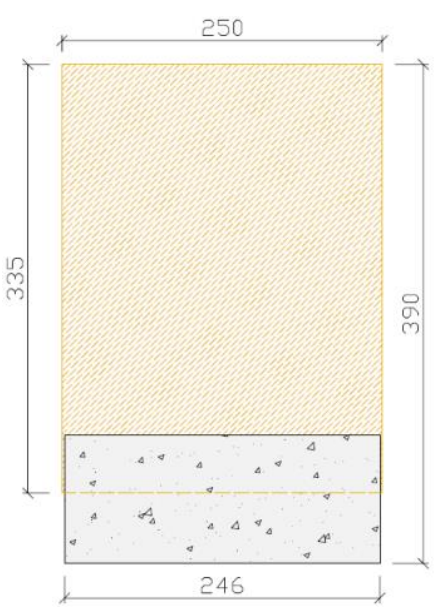

(b)

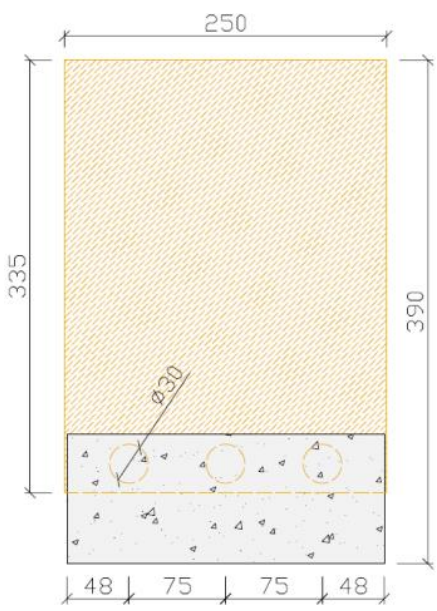

(d)

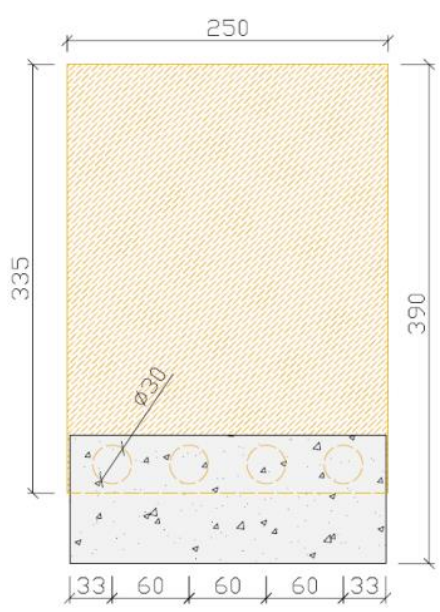

(e)

Figure 7: Layout of specimens: (a) front view and (b) lateral view of $0 \mathrm{H}$ connector; (c) front view of PERFOFRP connectors; (d) lateral view of $3 \mathrm{H}$ connector; (e) lateral view of $4 \mathrm{H}$ connector (dimensions in millimeter).

As shown in Figure 7, the geometry of the GFRP connectors was conditioned by the following constraints: diameter of the holes, thickness of the concrete layer, thickness of concrete cover (between the connector and the mould), and thickness of concrete above the hole. Taking into account these variables, a constant diameter of $30 \mathrm{~mm}$ was assumed for the holes on the GFRP plates in all perforated connectors, which allows the passage of aggregates (max. diameter equal to $12 \mathrm{~mm}$ ) throughout the holes.

The thickness of the concrete blocks was different of the concrete layers of the sandwich panels (i.e., $60 \mathrm{~mm}$ of thickness) proposed by the authors in a previous work [9]. The option for a thicker concrete block in this research has the purpose of decreasing the flexural stresses in the concrete during the pull-out tests, in an attempt of avoiding premature ruptures through concrete. Nonetheless, the depth of embedment of the GFRP connector remains equal to that used in the previous work $(45 \mathrm{~mm})$, in order to be representative of the connection in a sandwich panel 
comprising SFRSCC layers with $60 \mathrm{~mm}$ of thickness. The concrete cover of the connectors was kept constant and equal to $55 \mathrm{~mm}$ in all the specimens (see Figure 7). This value would correspond to a SFRSCC cover of $15 \mathrm{~mm}$ in case of a SFRSCC layer thickness of $60 \mathrm{~mm}$ in the sandwich panel, which is near the minimum acceptable for assuring proper concrete flow conditions in these zones. With these aforementioned values, the thickness of concrete above the holes was equal to $7.5 \mathrm{~mm}$ (see Figure 7c). The GFRP connectors were $250 \mathrm{~mm}$ wide and $335 \mathrm{~mm}$ tall. The slightly larger width of the connector as compared to the concrete block (250mm vs $246 \mathrm{~mm})$ was related to the ease in fixation of the connector to the form, thus facilitating casting procedures, as shown in Figure 8 . The connectors were cut out from GFRP flat plates with approximately $2.5 \mathrm{~m} \times 2.0 \mathrm{~m}$ and, for the PERFOFRP connectors, the holes were drilled afterwards.

Concrete blocks were cast orthogonally to their largest surfaces, in order to reproduce, as much as possible, the casting procedures adopted for the sandwich panels (see Figure 8). To also reproduce the fabrication conditions, the connectors were positioned and fastened to the mould prior to the concrete pouring (see Figure 8). Placing the $\mathrm{z}$

connector in-place before casting instead of after casting allows better $\underset{\mathrm{X}}{\mathrm{y}}$ assurance of the existence of fibres passing through the holes of PERFOFRP connectors (thus improving shear behavior of the dowel as compared to plain concrete).

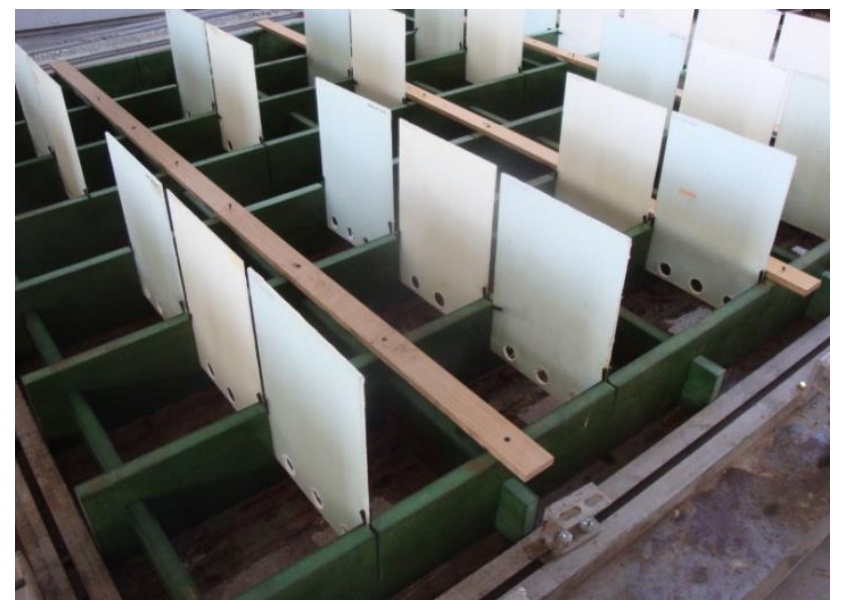

(a)

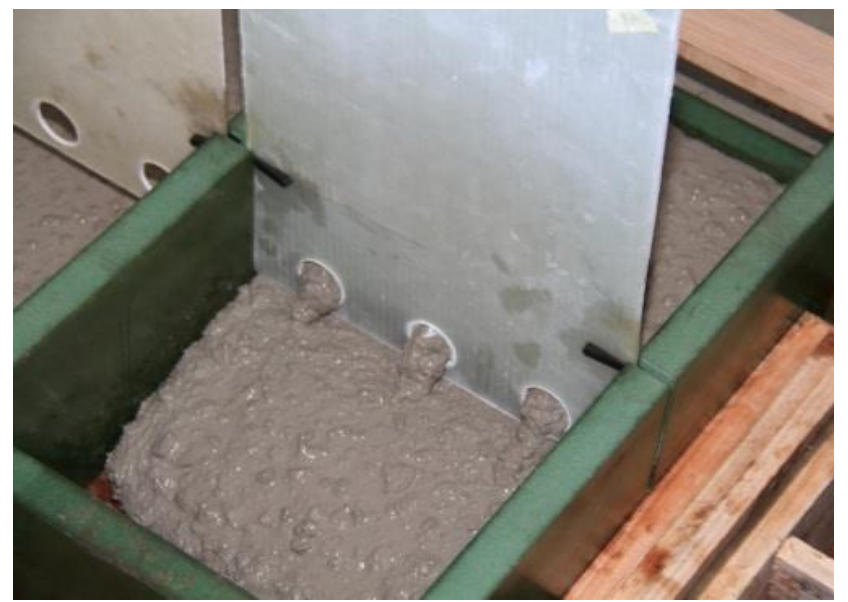

(b)

Figure 8: Production of pull-out specimens: (a) overall view of formwork; (b) pouring of 3H-MU4-SCC specimen.

The test variables were the number of holes on the GFRP connector (0, 3 or 4), the type of GFRP (CSM and MU4), and the type of concrete (SCC and SFRSCC). Figure 9 presents an overview of the executed experimental program, as well as the nomenclature for the tested specimens. The following designations are adopted: $0 \mathrm{H}-$ without holes; 3H - with 3 holes; 4H - with 4 holes; CSM - chopped GFRP strand mat; MU4 - multidirectional GFRP; SFRSCC steel fibre reinforced self-compacting concrete; SCC - self-compacting concrete. The configurations of the 
perforated connectors are shown in Figure 7. The distance between holes were $2.5 \cdot D(D-$ diameter of the hole) and 2.0. $D$ for the connectors with 3 and 4 holes, respectively. These values are near the distance of $2.25 \cdot D$ indicated by Oguejiofor and Hosain [20] as the minimum distance between holes to avoid the deleterious influence of adjacent concrete pins on the dowel effect. Hereinafter, in coherence with the scheme of Figure 9, the specimens are labeled as "XH-YYY-Z", where "X" refers to the number of holes (i.e.: $0 \mathrm{H}, 3 \mathrm{H}$ or 4H), "YYY" refers to the type of GFRP laminate (i.e.: CSM or MU4) and "Z" refers to the type of concrete adopted (i.e.: SCC or SFRSCC).

In general, 3 specimens for each type were tested, except for type 3H-CSM-SCC, OH-MU4-SFRSCC and 0H-MU4SCC, where only 2 specimens were tested.

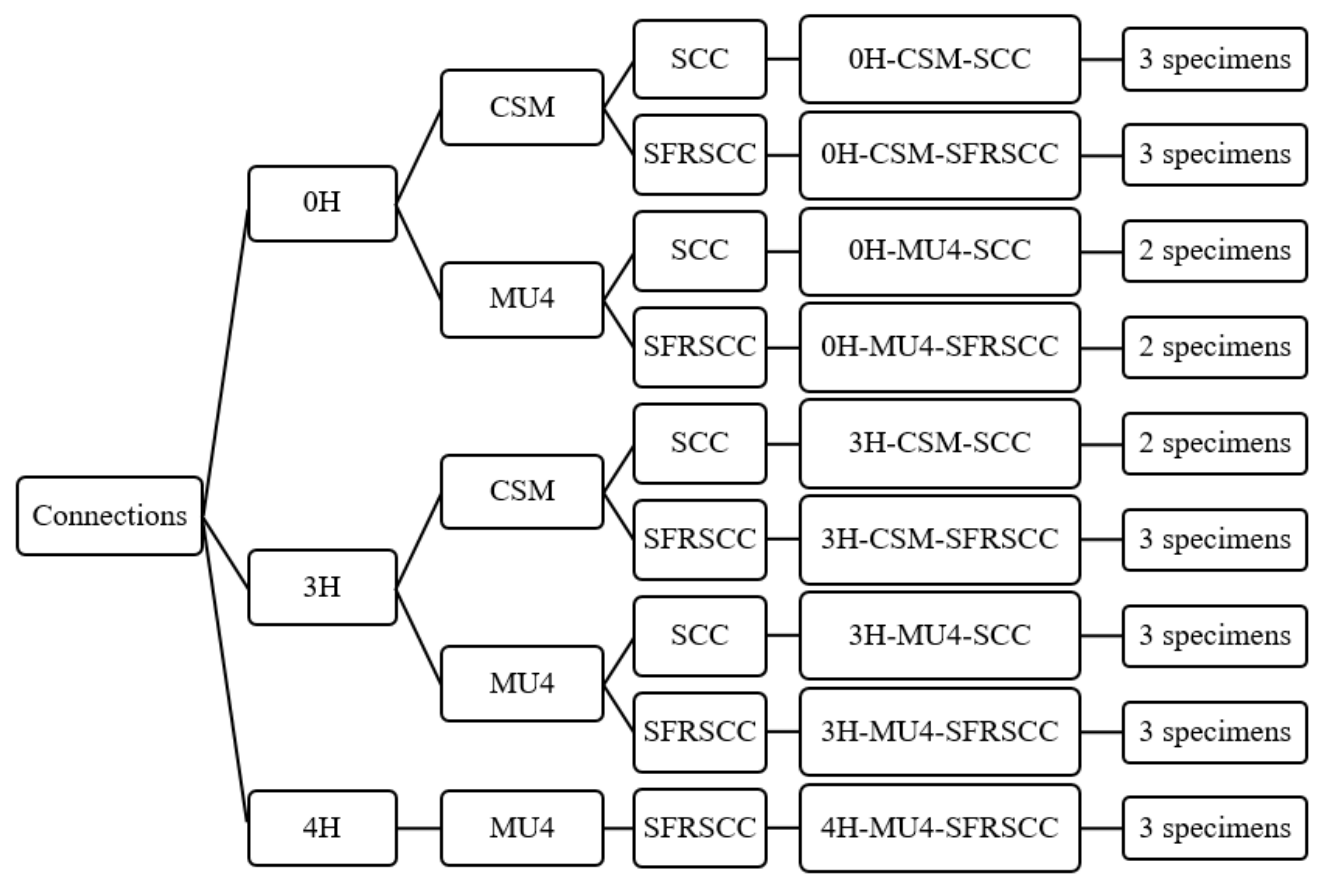

Figure 9: Experimental program: nomenclature of specimens and overall explanation.

\subsection{Pull-out tests}

The pull-out test setup is shown in Figure 10. Tests were performed in displacement control with a rate of $0.6 \mathrm{~mm} / \mathrm{min}$ using a universal testing machine. As can be observed from Figure 10, the movement of the concrete block of each specimen was restrained by two stiff steel bars (one in each side of the GFRP plate) by close tightening four high strength threaded rods of $20 \mathrm{~mm}$ diameter fixed to the base of the testing machine. The stiff steel bars have a square cross section of $40 \mathrm{~mm}$ edge and are distanced $200 \mathrm{~mm}$ from each other (see Figure 10). The vertical load was applied to the GFRP making use of grips where steel plates were tightened to the GFRP plate with four high strength steel bolts. The inner surfaces of such steel plates were made rough in order to increase their bond to the GFRP connector. An anchorage length of the GFRP laminate of $150 \mathrm{~mm}$ was always adopted to assure its proper gripping to the testing machine. A hinged connection was adopted between the gripping system and the 
testing machine in order to reduce the bending effect of a possible misalignment of the specimen in relation to loading axis of the testing machine (see Figure 10).

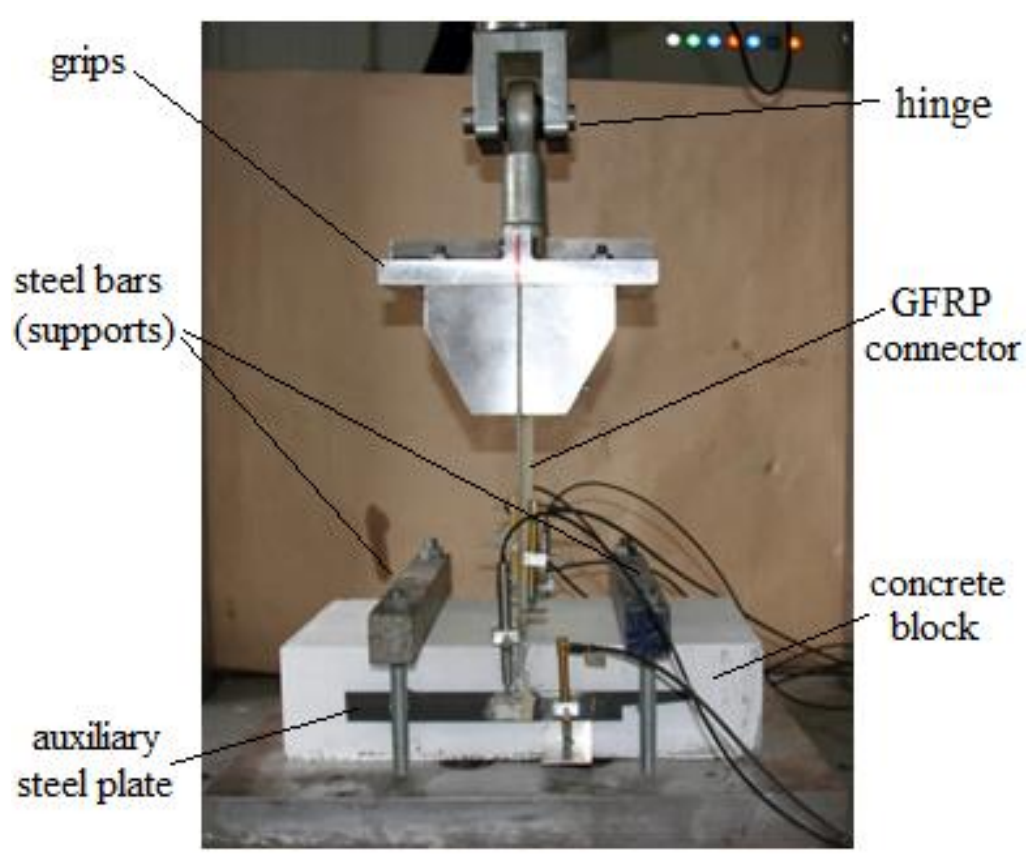

(a)

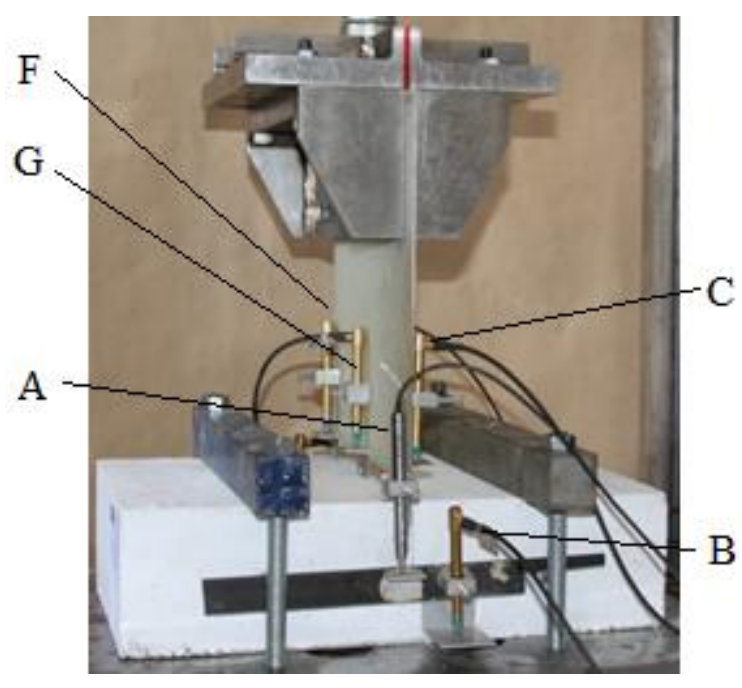

(b)

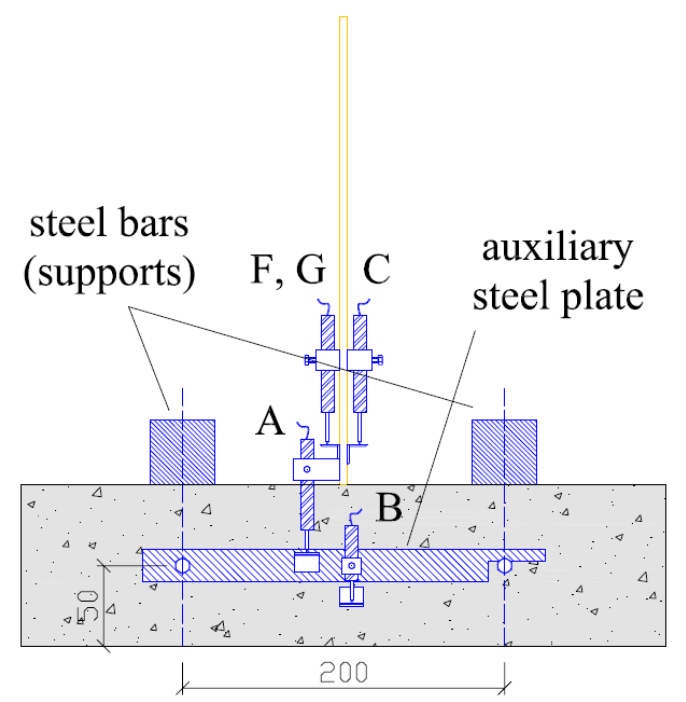

(c)

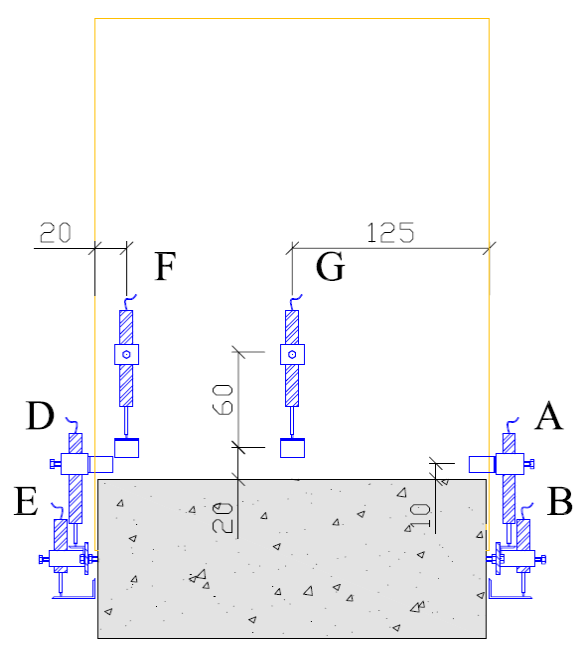

(d)

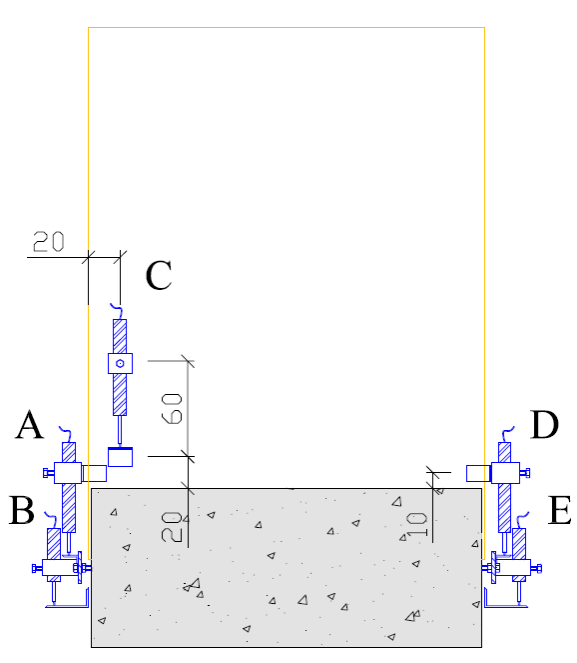

(e)

Figure 10: Pull-out test setup: (a) overall view. (b) Schematic representation of layout of LVDTs: (c) front view, (d) left view, (e) right view (dimensions in millimeter).

The specimens were properly instrumented with linear variable displacement transducers (LVDTs) to monitor strains in selected zones of the GFRP laminate out of the concrete block, as well as the differential displacement (slip) occurring between the GFRP laminate and the concrete block. In particular: 
- LVDTs A and D monitored the relative displacement between the GFRP laminate and the auxiliary steel plate fixed to the concrete block, in the front and rear sides of specimen, respectively. These LVDTs have a stroke of $\pm 10 \mathrm{~mm}$;

- LVDTs B and E monitored the deflection of the concrete block in the mid-span position in the front and rear sides of specimen, respectively. The deflection is obtained from measurements with the LVDTs fixed to the auxiliary steel bar in order do not include parasitic displacements [38]. The deflection of concrete block is used to control the overall behaviour of specimen during the tests, and to obtain the real slip between the GFRP laminate and the concrete block. These LVDTs have a stroke of $\pm 2 \mathrm{~mm}$;

- $\quad$ LVDTs $\mathrm{C}, \mathrm{F}$ and $\mathrm{G}$ were used to evaluate the average strains in the GFRP regions between the supporting points of these LVDTs, which were separated by $60 \mathrm{~mm}$. For practical reasons, these supporting points were distanced $10 \mathrm{~mm}$ and $70 \mathrm{~mm}$ from the top surface of the specimen (see Figure 10). A main concern of the test setup adopted was related to the possible existence of high bending stresses/strains that result from an eventual misalignment between the specimen and the loading axis of the machine. Making measurements of strain in the GFRP in both sides of the laminate and in different positions along the width of specimen was considered a good a way to control and evaluate the quality of the test results. These LVDTs have a stroke of $\pm 2 \mathrm{~mm}$.

To minimize potential effects of bending, the real slip between the GFRP connector and the concrete block was obtained for each specimen as the average value from the front and rear side of the specimen. The real slip in the front of the specimen was obtained by subtracting the measurement of LVDT B from the measurement of LVDT A, while the real slip in the rear side of the specimen was obtained by subtracting the measurement of LVDT E from the measurement of LVDT D.

The applied load was registered by a $200 \mathrm{kN}$ load cell attached to the piston of the actuator. The acquisition system was set to continuously acquire the raw data at $2 \mathrm{~Hz}$.

The surface cracks in the concrete blocks were identified during the loading process. The test was finished when the specimen was already in its softening stage, at a load decay of at least $50 \%$ in regard to the registered peak load.

\subsection{Experimental results}

\subsubsection{Failure mode}

The interpretation of the failure modes is made taking into account the observations made during the tests and also the post testing inspection of the specimens. The interpretation of the damages observed in the embedded part of the GFRP plate was based on this post testing inspection. 
It was observed that, in general, independently of the type of concrete and of the connector, for a certain load stage the interface between concrete block and GFRP connector started to become disconnected, which generated in a crack that has progressively propagated towards the bottom surface of the block, as shown in Figure 11, by splitting the concrete block in two parts. For the specimens with SCC, this almost vertical crack developed rapidly throughout the entire thickness of the specimen when the peak load was reached, with a crack width that continuously got wider, and at the end of the test the maximum crack width was larger in the SCC than when using SFRSCC. On the other hand, in the specimens with SFRSCC, the crack width propagation was arrested by the steel fibres bridging the crack, keeping the width much lower.

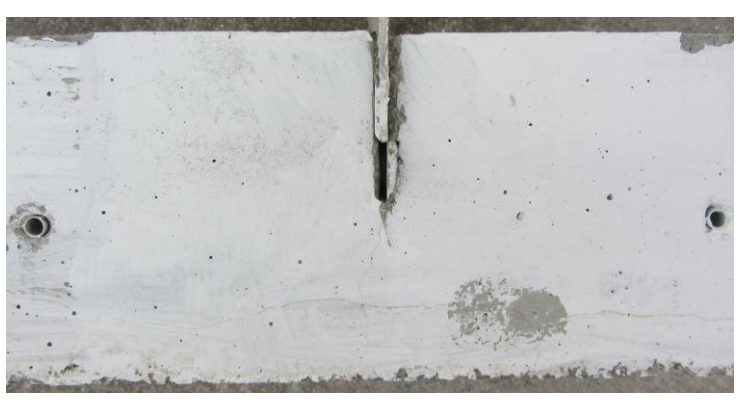

(a)

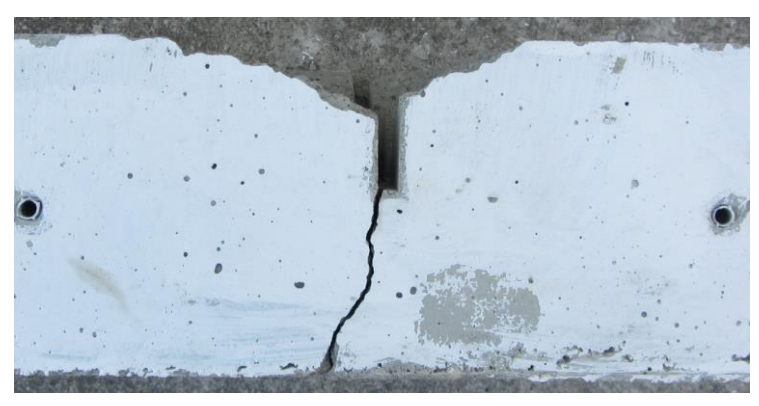

(b)

Figure 11: Detail of typical vertical cracking of concrete blocks: (a) 3H-CSM-SFRSCC and (b) 3H-CSM-SCC.

For the specimens made with CSM PERFOFRP connectors, the failure occurred due to the rupture of the connector in the vicinity of the holes (see Figure 12). This behaviour was observed for specimens with SCC and SFRSCC blocks. An exception occurred in 3H-CSM-SCC 01 specimen, where no rupture of the connector was observed. For the connectors made with the CSM laminate three typical failure lines were observed in the vicinity of holes of GFRP connectors: two inclined approximately $45^{\circ}$ and one $90^{\circ}$ with the horizontal (see Figure 13). These failure lines generally crossed the connector from the hole edge to the connector bottom edge (see Figure 13). Apparently, the CSM connectors were not capable of causing a shear failure of the concrete dowels. Possibly because the rupture of the connector itself occurs before the shear strength related to the rupture by shear in the surface between the PERFOFRP connector and the concrete block, due the combined effect of concrete dowel and friction/adhesion, is attained. Similar failure modes were obtained in the preliminary pull-out tests performed by the authors [9].
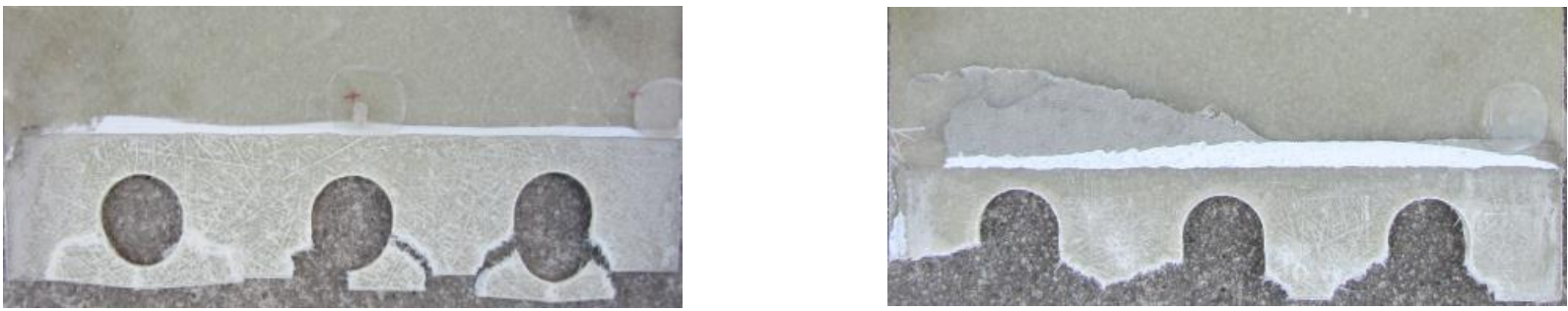
(a)

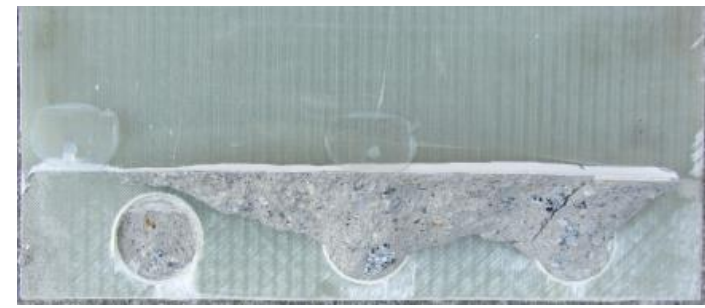

(c)

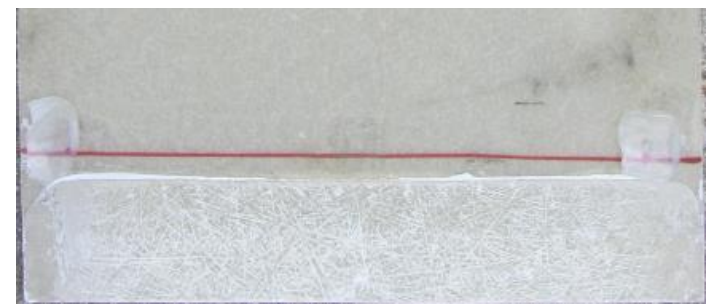

(e) (b)

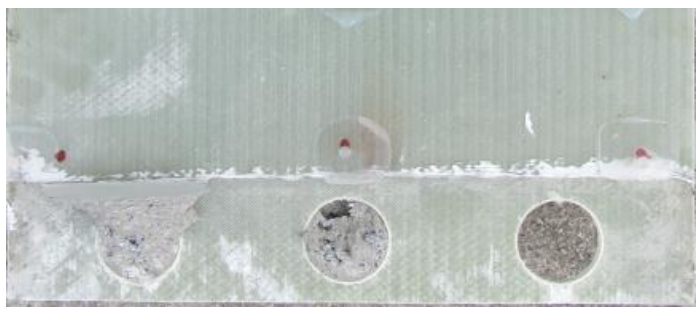

(d)

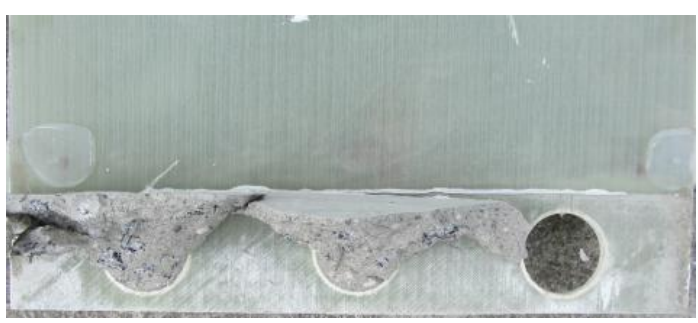

(f)

Figure 12: Representative aspect of GFRP connectors after failure: (a) 3H-CSM-SCC 02; (b) 3H-CSM-SFRSCC 01; (c) 3HMU4-SCC 01; (d) 3H-MU4-SFRSCC 02; (e) 0H-CSM-SFRSCC 01; (f) 4H-MU4-SFRSCC 01.

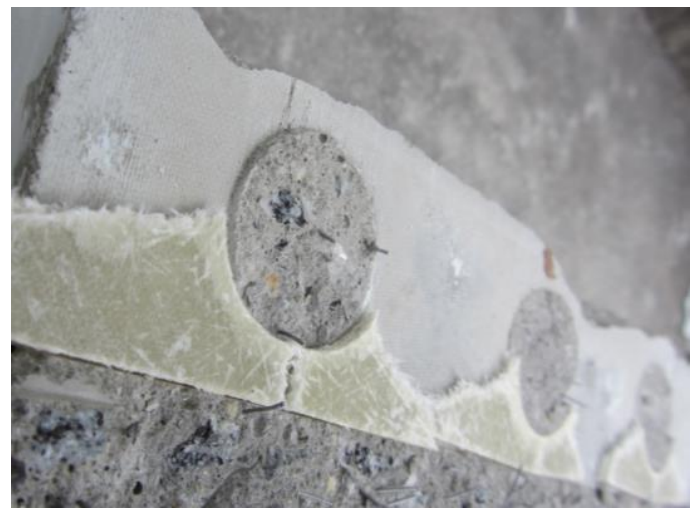

(a)

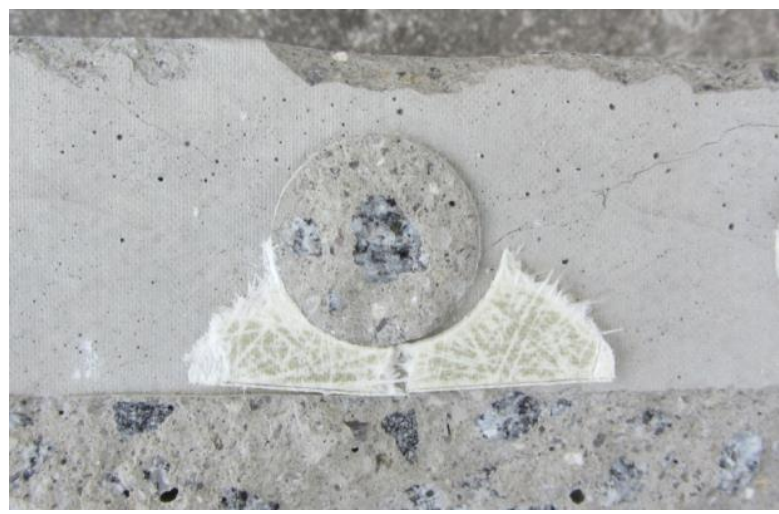

(b) 
Figure 13: Detail of typical failure modes of specimens comprising CSM laminate with holes: (a) 3H-CSM-SFRSCC; (b) 3H-CSM-SCC.

Due to the larger thickness of the MU4 laminate, rupture of the concrete block was observed in the corresponding specimens. As observed in Figure 12d and Figure 14a, a slice of the concrete dowel remains in many holes at the end of the tests. These observations confirm the higher efficacy of this type of connector in mobilizing the concrete dowels. In fact, concrete failure was the dominant failure mode in the specimens with MU4 laminate. Two main types of failure were observed: shear failure along the interface plans between both materials (shear failure of the concrete dowels plus shear failure by friction/adhesion) and concrete cone failure. Sometimes both failure modes were observed for different holes of the same connector (see Figure 14a). Possibly this occurred due to an occasional difference of stiffness of the concrete dowels, any geometrical imperfection, eccentricity of the load applied to the specimen, or any combination of these effects. Apparently, the connectors produced with MU4 laminate would be able to attain higher loads, since the small embedment depth of the dowels/holes, which was limited by blocks imposed restrictions (i.e.: thickness of concrete layer, minimum distance between the connector and the mould, etc), has promoted the occurrence of a premature rupture by the formation of a superficial concrete cone (see Figure 14b).

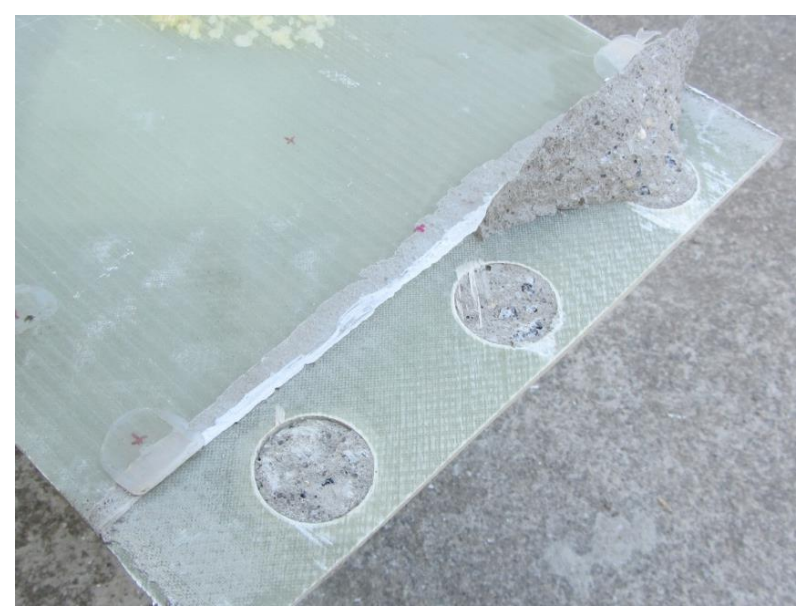

(a) 


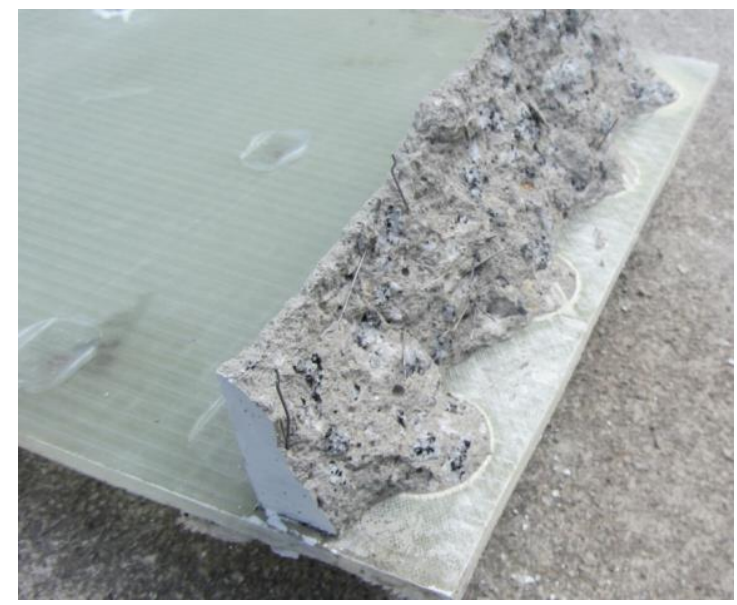

(b)

Figure 14: Detail of typical failure modes of specimens comprising MU4 laminate with holes: (a) 3H-MU4SCC; (b) 4H-MU4-SFRSCC.

The failure modes obtained for the connections consisting MU4 PERFOFRP connectors with 3 and 4 holes were quite similar. For all the specimens, it was observed the formation of ruptured concrete cones that extended from the top surface of the concrete blocks and with their apex in the lower edge of the concrete dowels formed by the passage of concrete through the holes of the connectors (Figure 14a). The horizontal distance measured in the top surface of the concrete block from the connector to the crack corresponded to the concrete cone had an average length of approximately $35 \mathrm{~mm}$. Considering the apex of the cone in the point immediately below the hole, located at a depth measured $30 \mathrm{~mm}+7.5 \mathrm{~mm}$ vertically from the top surface of the concrete block, it is obtained that the angle between the surface of the cone and the horizontal was equal about $47^{\circ}$. In any case, the failure line did not reached the supports (i.e.: the stiff steel bars positioned on the top surface of concrete blocks). It was also noticed that the fracture lines that defined the concrete cone generally did not appear at the same instant in both sides of specimens.

With regard to the GFRP laminates without holes, such as specimens OH-CSM-SCC, OH-CSM-SFRSCC, OH-MU4SCC and OH-MU4-SFRSCC, no damage was visible in the GFRP, apart some superficial scratches resulting from friction between the concrete block and the GFRP (see Figure 12e).

\subsubsection{Engineering normal strain in the laminate}

Table 12 presents the maximum engineering normal strains obtained from the measurements of LVDTs C, F and G, positioned in the region of the GFRP between the concrete block and the grips.

Comparing the values registered by the different LVDTs in each test, it can be observed that there are significant differences between the tensile strains in the monitored regions of the laminate. These values indicate the existence 
of bending in the laminates during the tests, which is almost impossible to exclude completely, regardless the type of test setup used. The relevant information extracted from these results is that the maximum registered strains $\left(\varepsilon_{\max }\right)$ were much lower than the ultimate strain of the adopted GFRPs $\left(\varepsilon_{p t . u}\right)$, never exceeding $17 \%$ (see Table 12 Table 10). It can be concluded that for the configuration adopted for the connections, regardless the type of concrete, connector (with or without holes) and type of GFRP (CSM or MU4), the laminates were always far from the rupture in the region between the concrete block and the grips.

Table 5: Maximum engineering normal strains in the region of the GFRP connectors between the concrete block and the grips.

\begin{tabular}{|c|c|c|c|c|c|}
\hline \multirow[b]{2}{*}{ Specimen } & \multicolumn{3}{|c|}{ Maximum strain $-\varepsilon_{\max }[\mu \varepsilon]$} & \multirow[b]{2}{*}{$\varepsilon_{\max } / \varepsilon_{\text {pt.el }}$} & \multirow[b]{2}{*}{$\varepsilon_{\max } / \varepsilon_{\text {pt.u }}$} \\
\hline & $\begin{array}{c}\text { LVDT } \\
\text { C }\end{array}$ & $\begin{array}{c}\text { LVDT } \\
\mathrm{F}\end{array}$ & $\begin{array}{c}\text { LVDT } \\
\text { G }\end{array}$ & & \\
\hline 3H-CSM-SCC 01 & 1737.45 & 1028.35 & 1429.10 & $9.6 \%$ & $9.6 \%$ \\
\hline 3H-CSM-SCC 02 & 3439.05 & 1966.92 & 2038.25 & $19.1 \%$ & $11.3 \%$ \\
\hline 3H-CSM-SFRSCC 01 & 2572.97 & 802.40 & 1317.38 & $14.3 \%$ & $7.3 \%$ \\
\hline 3H-CSM-SFRSCC 02 & 13.70 & 1291.03 & 1397.68 & $7.8 \%$ & $7.8 \%$ \\
\hline 3H-CSM-SFRSCC 03 & 3108.87 & 2973.08 & 2901.40 & $17.2 \%$ & $16.5 \%$ \\
\hline 3H-MU4-SCC 01 & 1252.20 & 58.22 & 949.57 & $25.0 \%$ & $3.5 \%$ \\
\hline 3H-MU4-SCC 02 & 1625.63 & 997.30 & 1109.77 & $32.4 \%$ & $4.1 \%$ \\
\hline 3H-MU4-SCC 03 & 1562.33 & 890.83 & 709.28 & $31.1 \%$ & $3.3 \%$ \\
\hline 3H-MU4-SFRSCC 01 & 997.95 & 1474.75 & 1442.80 & $29.4 \%$ & $5.5 \%$ \\
\hline 3H-MU4-SFRSCC 02 & 1467.40 & 990.92 & 1115.03 & $29.3 \%$ & $4.2 \%$ \\
\hline 3H-MU4-SFRSCC 03 & 974.75 & 1129.57 & 1396.43 & $27.8 \%$ & $5.2 \%$ \\
\hline 0H-CSM-SCC 01 & 953.65 & 2321.23 & 3073.20 & $17.0 \%$ & $17.0 \%$ \\
\hline OH-CSM-SCC 02 & 2033.90 & 1609.22 & 1676.77 & $11.3 \%$ & $9.3 \%$ \\
\hline OH-CSM-SCC 03 & 2067.65 & 1938.27 & 1159.30 & $11.5 \%$ & $10.8 \%$ \\
\hline 0H-CSM-SFRSCC 01 & $*$ & $*$ & $*$ & $*$ & $*$ \\
\hline 0H-CSM-SFRSCC 02 & 1298.60 & 341.58 & 1607.20 & $8.9 \%$ & $8.9 \%$ \\
\hline OH-CSM-SFRSCC 03 & $*$ & 1344.97 & 1503.92 & $8.3 \%$ & $8.3 \%$ \\
\hline 0H-MU4-SCC 01 & 1126.67 & 1001.45 & 685.05 & $22.5 \%$ & $3.7 \%$ \\
\hline 0H-MU4-SCC 02 & 1480.07 & 236.78 & 201.30 & $29.5 \%$ & $0.9 \%$ \\
\hline 0H-MU4-SFRSCC 01 & 905.12 & 560.90 & 500.60 & $18.0 \%$ & $2.1 \%$ \\
\hline 0H-MU4-SFRSCC 02 & 881.92 & 547.87 & 568.05 & $17.6 \%$ & $2.1 \%$ \\
\hline 4H-MU4-SFRSCC 01 & 1483.22 & 1406.83 & 981.20 & $29.6 \%$ & $5.3 \%$ \\
\hline 4H-MU4-SFRSCC 02 & 1162.53 & 809.03 & 537.48 & $23.2 \%$ & $3.0 \%$ \\
\hline 4H-MU4-SFRSCC 03 & $*$ & 923.28 & 993.83 & $19.8 \%$ & $3.7 \%$ \\
\hline
\end{tabular}




\subsubsection{Pull-out load capacity and load versus slip behaviour}

Table 13 summarizes relevant results obtained from the twenty four pull-out tests of the experimental program. In detail, such table reports the average values (avg.) and coefficient of variation $(\mathrm{CoV})$ of: the ultimate load ( $\left.Q_{t r . u}\right)$, the slip corresponding to the ultimate loads ( $\left.s_{t r . u}\right)$, the cracking load $\left(Q_{t r . c r}\right)$, the slip corresponding to the cracking loads $\left(s_{t r . c r}\right)$ and the initial stiffness $\left(K_{t r . i}\right)$

The ultimate load ( $\left.Q_{t r . u}\right)$ corresponds to the maximum load attained in each test. The cracking load $\left(Q_{t r . c r}\right)$ is the one for which the first crack appeared in the concrete block. The initial stiffness $\left(K_{t r . i}\right)$ of the connections was calculated from the equation:

$$
K_{t r . i}=\frac{Q_{t r .50}-Q_{t r .25}}{s_{t r .50}-s_{t r .25}}
$$

where $Q_{t r .50}$ and $Q_{t r .25}$ are the loads corresponding to $50 \%$ and $25 \%$ of the $Q_{t r . c r}$, respectively, while $s_{t r .50}$ and $s_{t r .25}$ are the corresponding slip. Representative pull-out load versus slip curves, with the identification of some of the observed failure modes, are depicted in Figure 15. The presented curves were obtained for each specimen averaging the slips measured in the front and rear sides of the specimen. Although some divergence was obtained in the results registered from the front and rear sides of the same specimen, it was observed that similar conclusions were taken when the data was analyzed separately or in terms of average values. Therefore, for the sake of brevity, in this article only the average values are presented. All the curves obtained in the pull-out tests are presented in Figure 16-Figure 18. The curves are grouped for helping in the analysis of the following effects: concrete type (Figure 16), type of GFRP laminate (Figure 17), and number of holes in the connector (Figure 18). In Table 13 and in the curves presented in Figure 15 to Figure 18, the load is indicated as "load per unit length of connector". This value was obtained dividing the experimental load by the width of the connector of specimen, that was $246 \mathrm{~mm}$.

Table 6: Results of pull-out tests: ultimate load $\left(Q_{t r . u}\right)$, slip corresponding to the ultimate load ( $\left.s_{t r . u}\right)$, cracking load $\left(Q_{t r . c r}\right)$, slip corresponding to the cracking load $\left(s_{t r . c r}\right)$ and initial stiffness $\left(K_{t r . i}\right)$.

\begin{tabular}{cccccccccccc}
\hline & \multicolumn{3}{c}{$Q_{t r . u}$} & \multicolumn{2}{c}{$s_{t r . u}$} & \multicolumn{2}{c}{$Q_{t r . c r}$} & \multicolumn{2}{c}{$s_{t r . c r}$} & \multicolumn{2}{c}{$K_{t r . i}$} \\
\cline { 2 - 11 } Connection & Avg. & Co & Avg. & $\begin{array}{c}\text { Co } \\
\text { V }\end{array}$ & Avg. & Co & Avg. & CoV & Avg. & Co \\
& {$[\mathrm{kN} / \mathrm{m}$} & {$[\%]$} & {$[\mathrm{mm}]$} & {$[\%]$} & {$[\mathrm{kN} / \mathrm{m}$} & {$[\%]$} & {$[\mathrm{mm}]$} & {$[\%]$} & {$[\mathrm{kN} / \mathrm{mm} / \mathrm{m}$} & {$[\%]$} \\
\hline 3H-CSM-SCC & 80.4 & 20 & 0.18 & 18 & 80.4 & 20 & 0.18 & 18 & 104.9 & 12 \\
3H-CSM-SFRSCC & 95.1 & 6 & 1.18 & 21 & 71.7 & 2 & 0.11 & 37 & 78.8 & 35 \\
3H-MU4-SCC & 93.4 & 7 & 0.31 & 104 & 86.2 & 2 & 0.07 & 23 & 193.3 & 13 \\
3H-MU4-SFRSCC & 108.2 & 7 & 1.25 & 44 & 71.2 & 12 & 0.05 & 31 & 145.3 & 30
\end{tabular}




\begin{tabular}{ccccccccccc} 
OH-CSM-SCC & 74.5 & 9 & 0.14 & 16 & 72.7 & 11 & 0.14 & 16 & 109.5 & 32 \\
0H-CSM-SFRSCC & 58.1 & 18 & 0.58 & 138 & 58.1 & 18 & 0.12 & 19 & 92.4 & 11 \\
OH-MU4-SCC & 88.8 & 13 & 0.10 & 64 & 88.8 & 13 & 0.10 & 64 & 143.7 & 2 \\
0H-MU4-SFRSCC & 80.9 & 2 & 0.14 & 30 & 80.9 & 2 & 0.14 & 30 & 119.1 & 13 \\
4H-MU4- & 112.1 & 2 & 0.40 & 2.97 & 83.1 & 5.9 & 0.05 & 31.4 & 180.8 & 32.2 \\
SFRSCC* & & & & & & & & 6 & \\
\hline
\end{tabular}

*- results of 4H-MU4-SFRSCC 02 were disregarded.

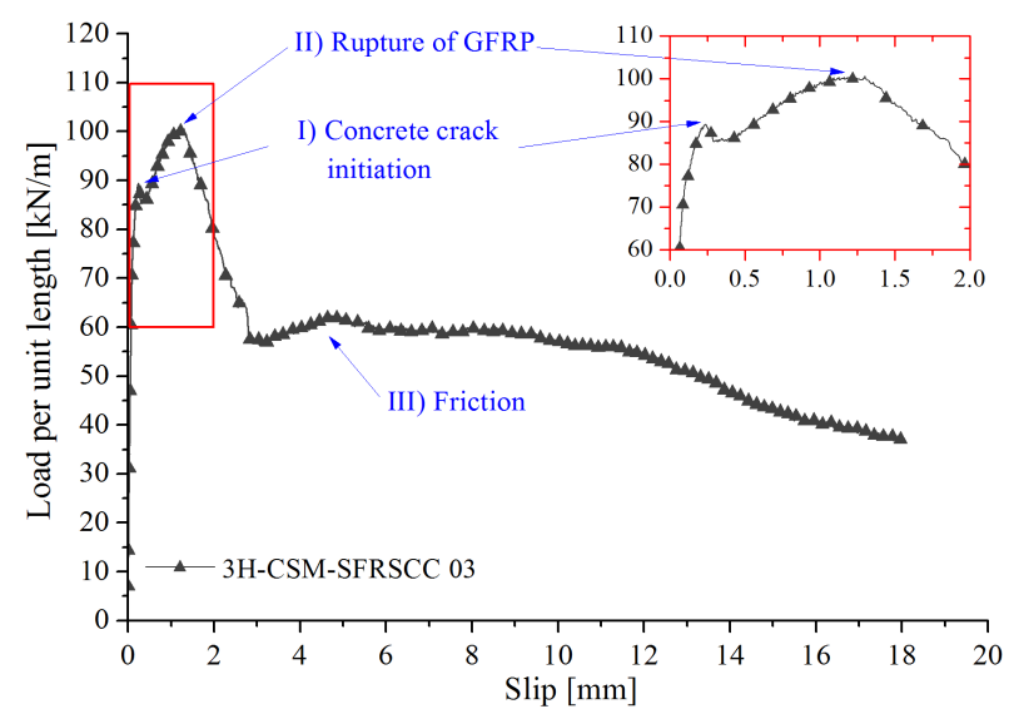

(a)

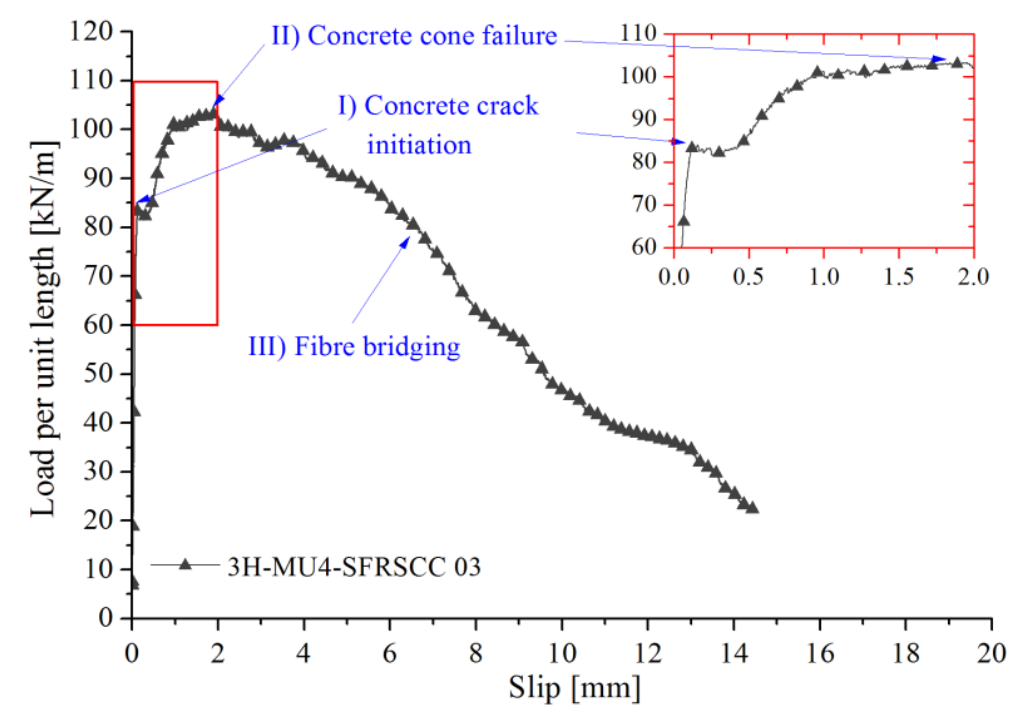

(b) 


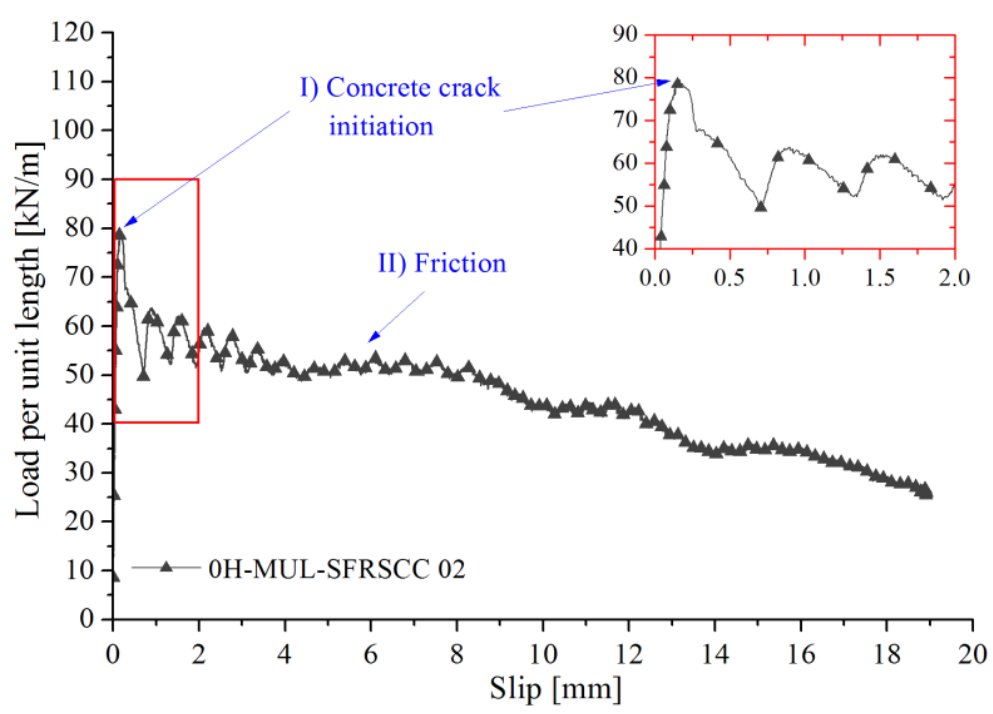

(c)

Figure 15: Representative pull-out load versus slip relationship, with identification of the observed failure modes: (a) 3H-CSM-SFRSCC; (b) 3H-MU4-SFRSCC and (c) 0H-MU4-SFRSCC.

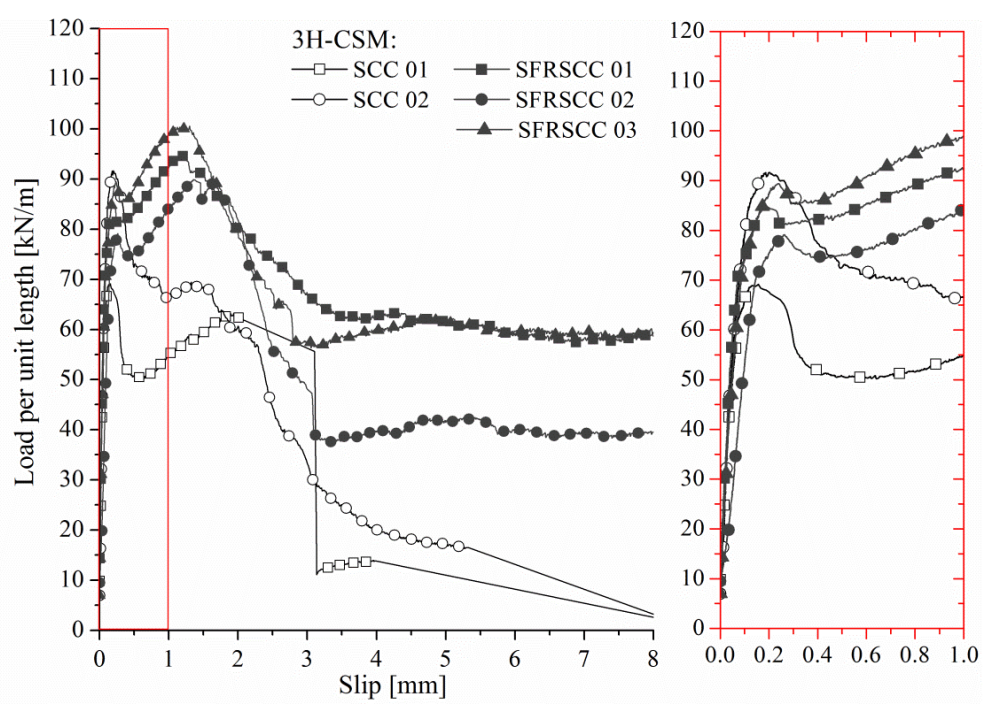

(a) 

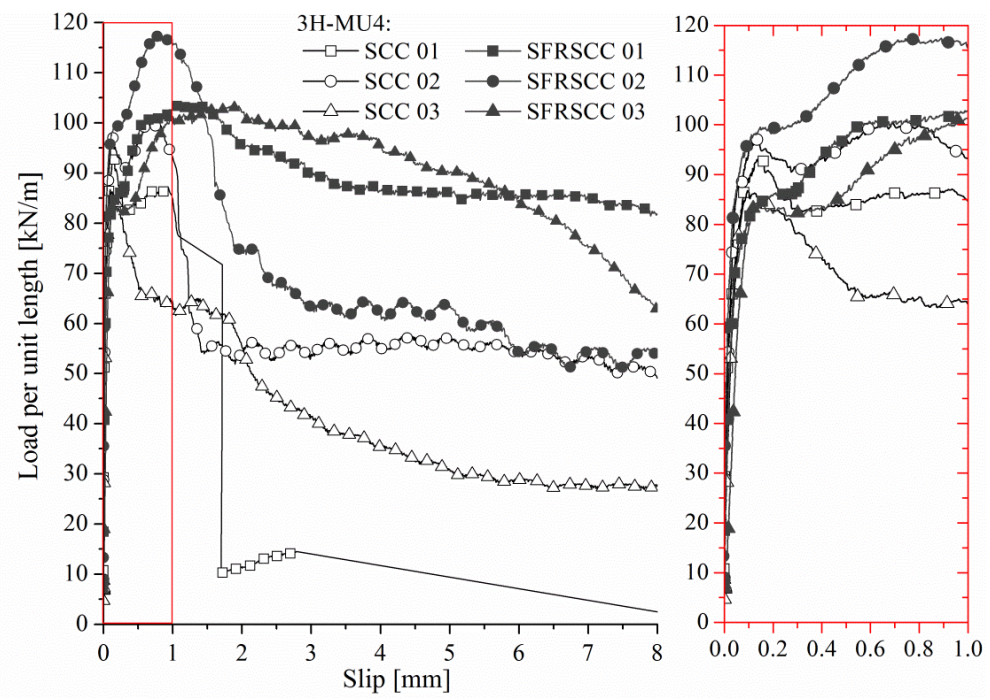

(b)
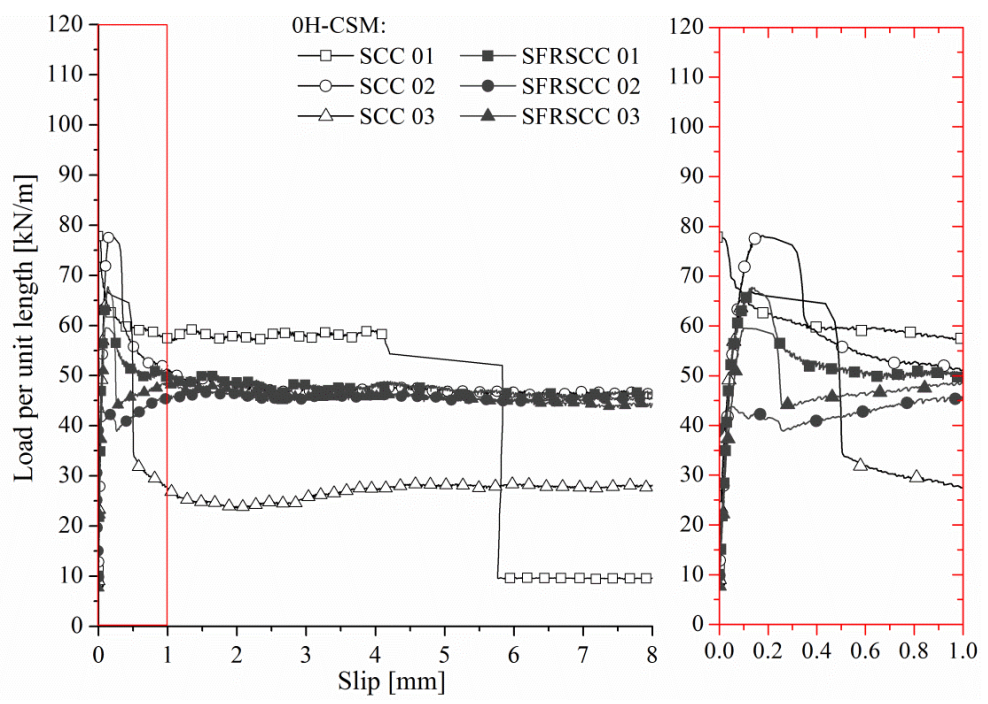

(c)
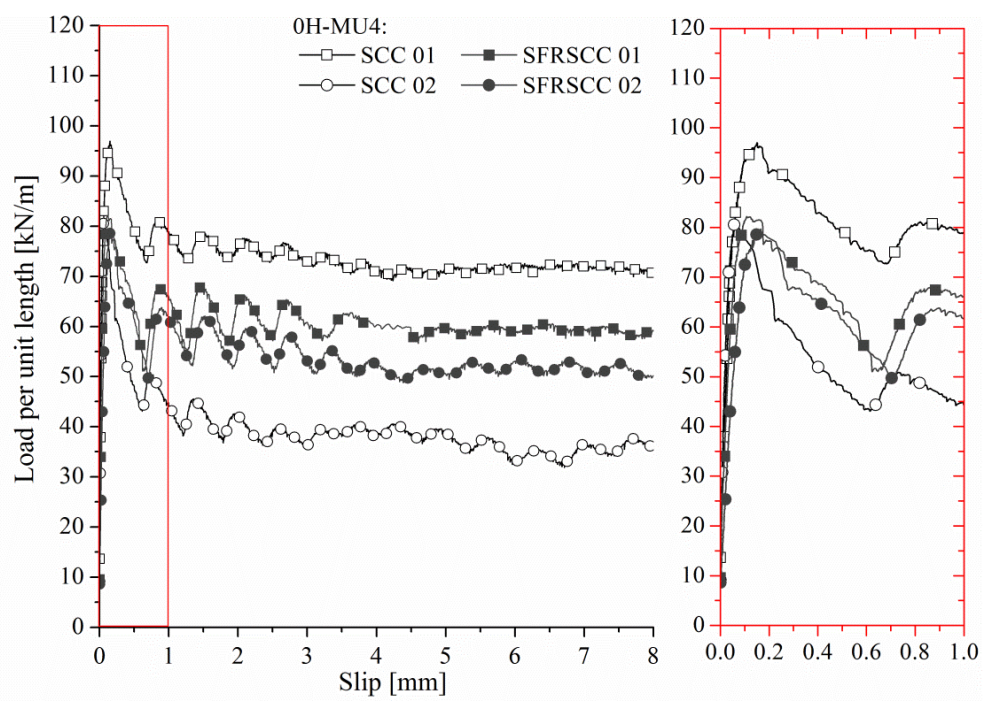

(d) 
Figure 16: Influence of the concrete type on the pull-out load versus slip relationship: (a) 3H-CSM; (b) 3H-MU4;

(c) $0 \mathrm{H}-\mathrm{CSM}$ and (d) $0 \mathrm{H}-\mathrm{MU} 4$.

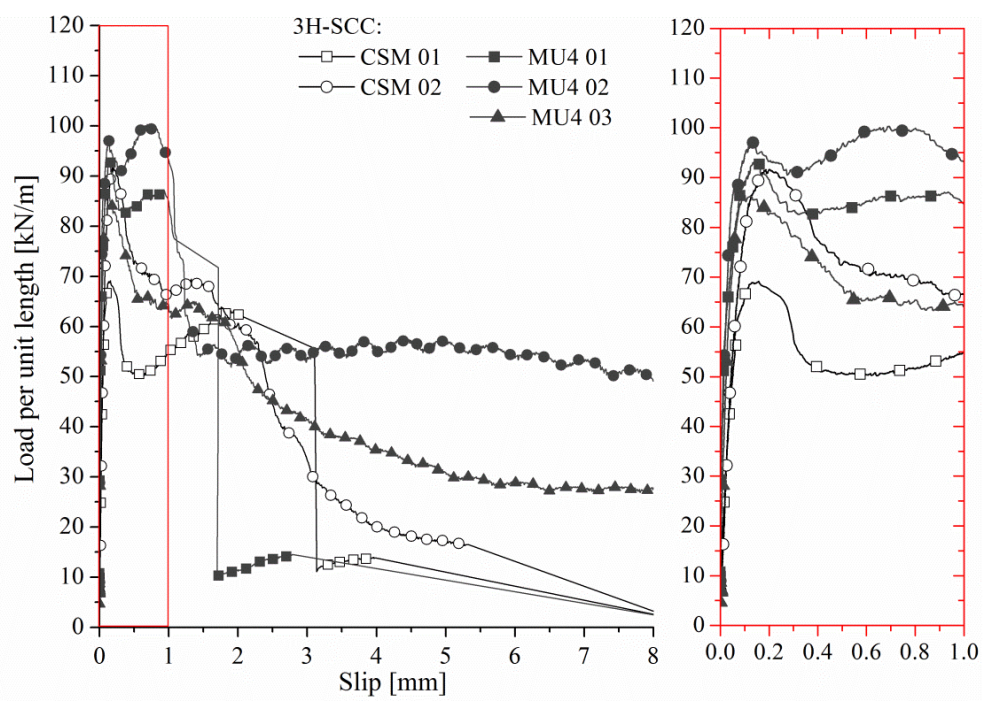

(a)

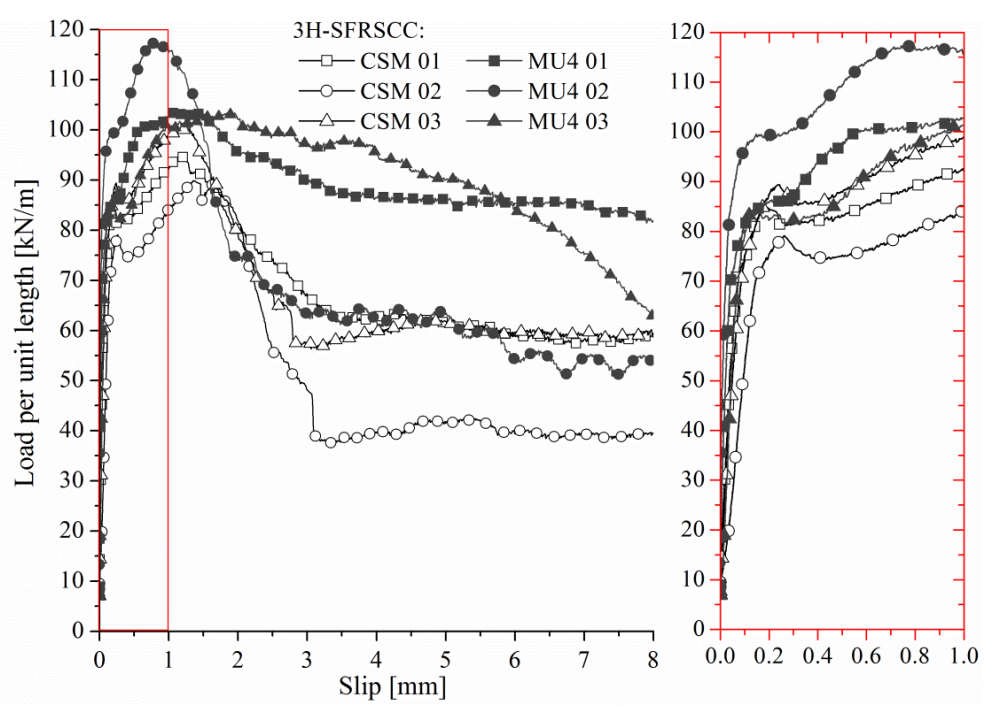

(b) 

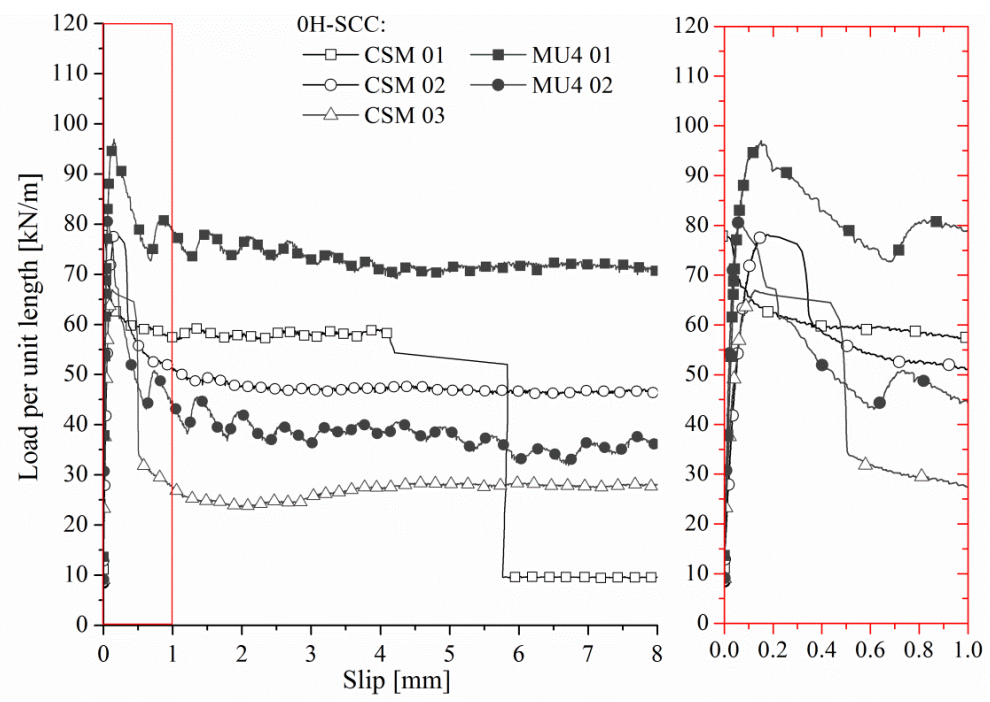

(c)

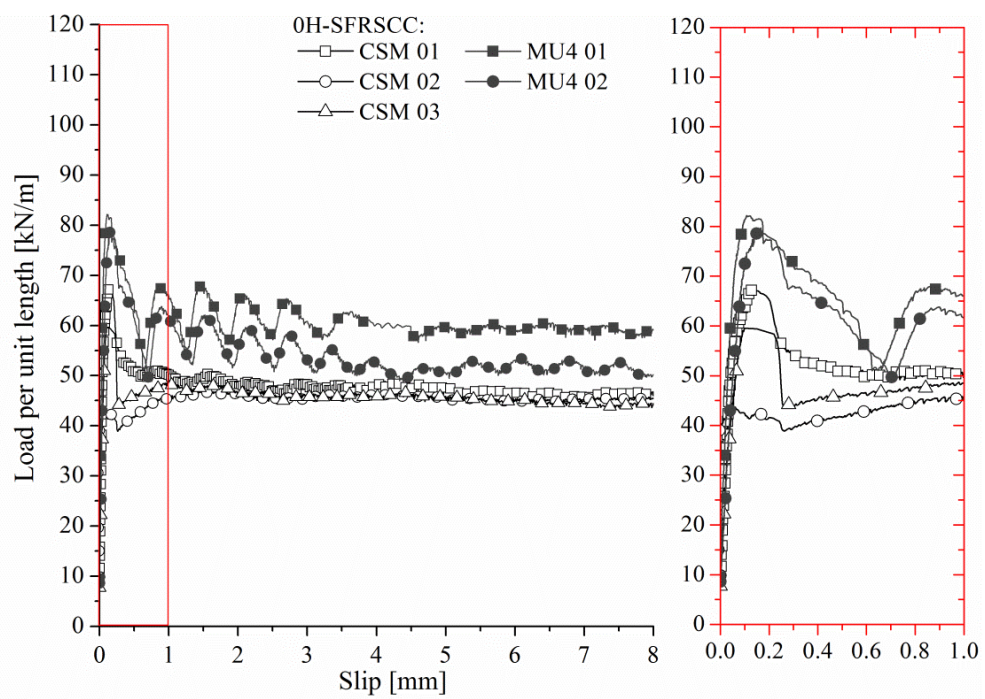

(d)

Figure 17: Influence of the GFRP laminate on the pull-out load versus slip relationship: (a) 3H-SCC; (b) $3 \mathrm{H}-$ SFRSCC; (c) 0H-SCC and (d) 0H-SFRSCC. 

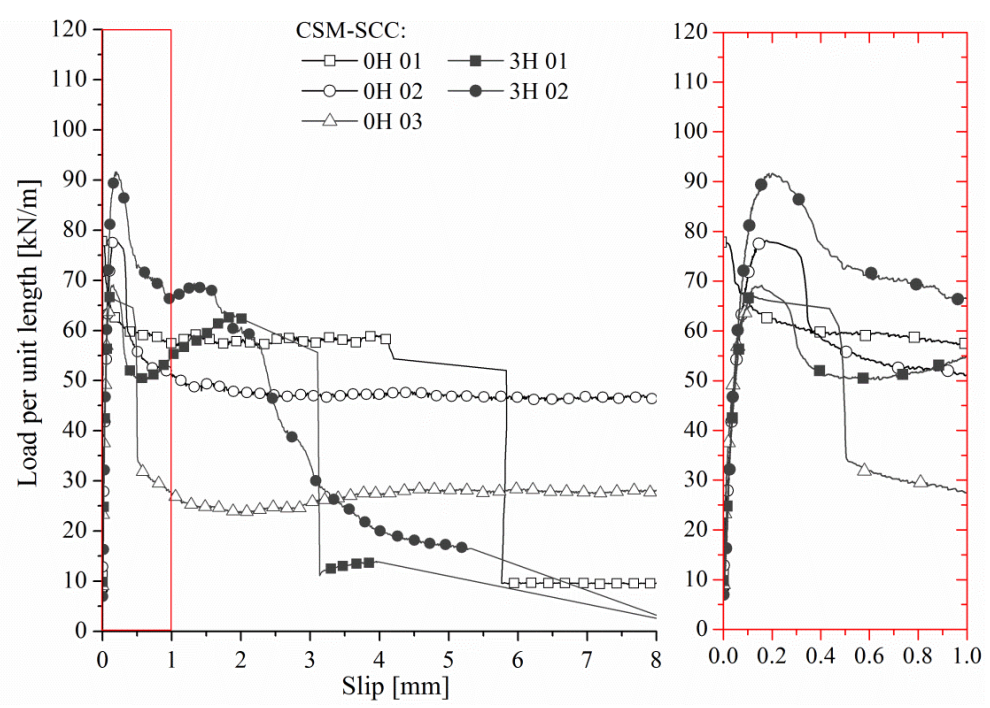

(a)
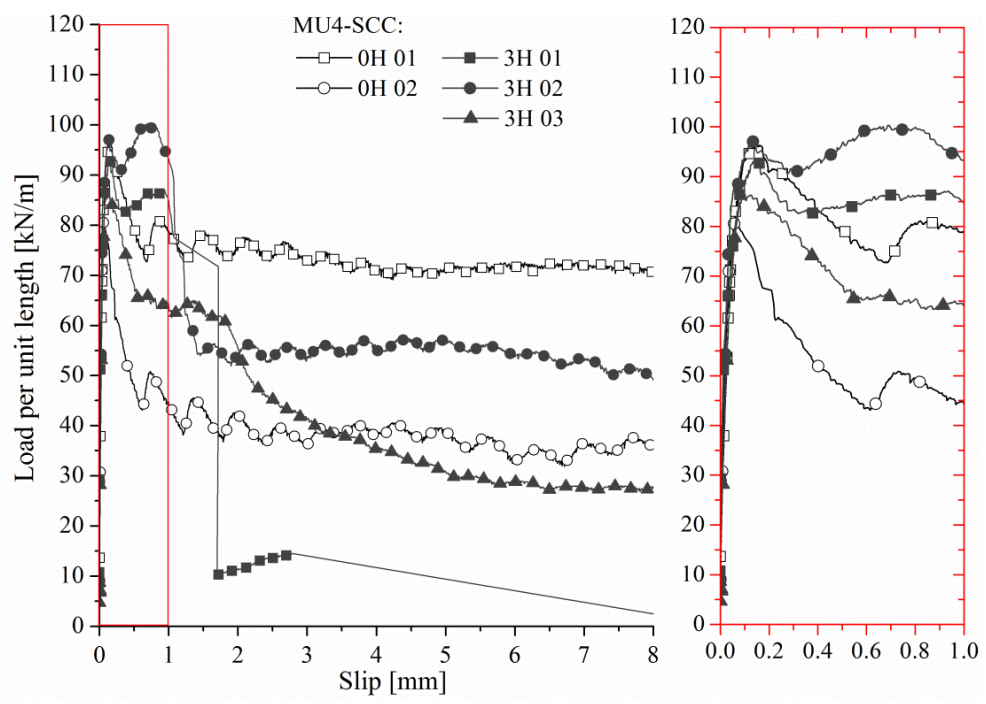

(b)
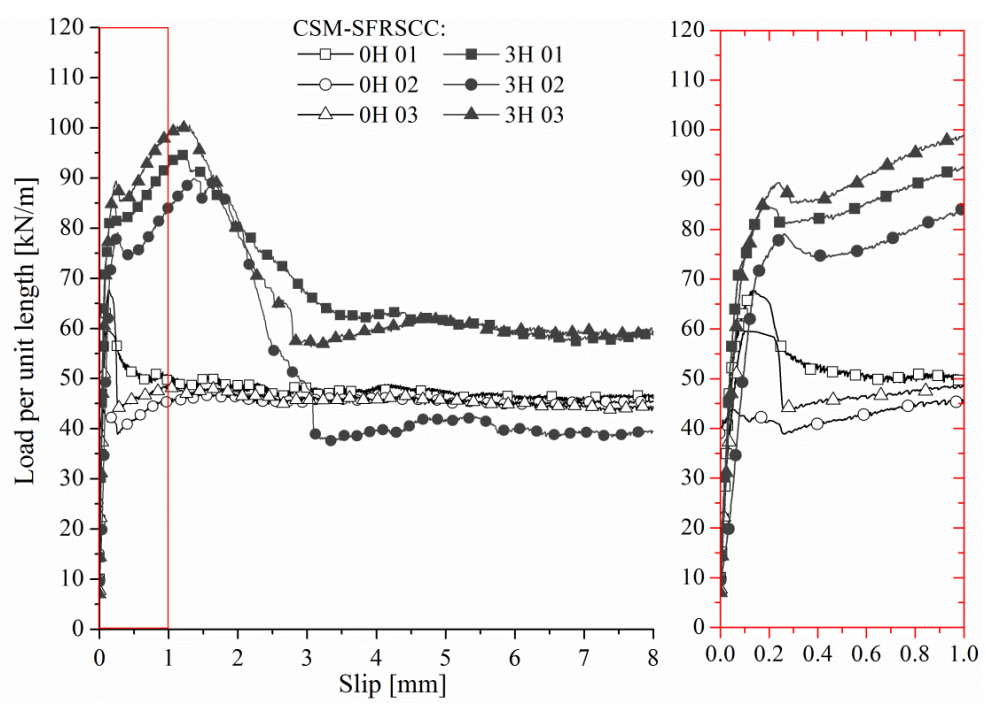

(c) 


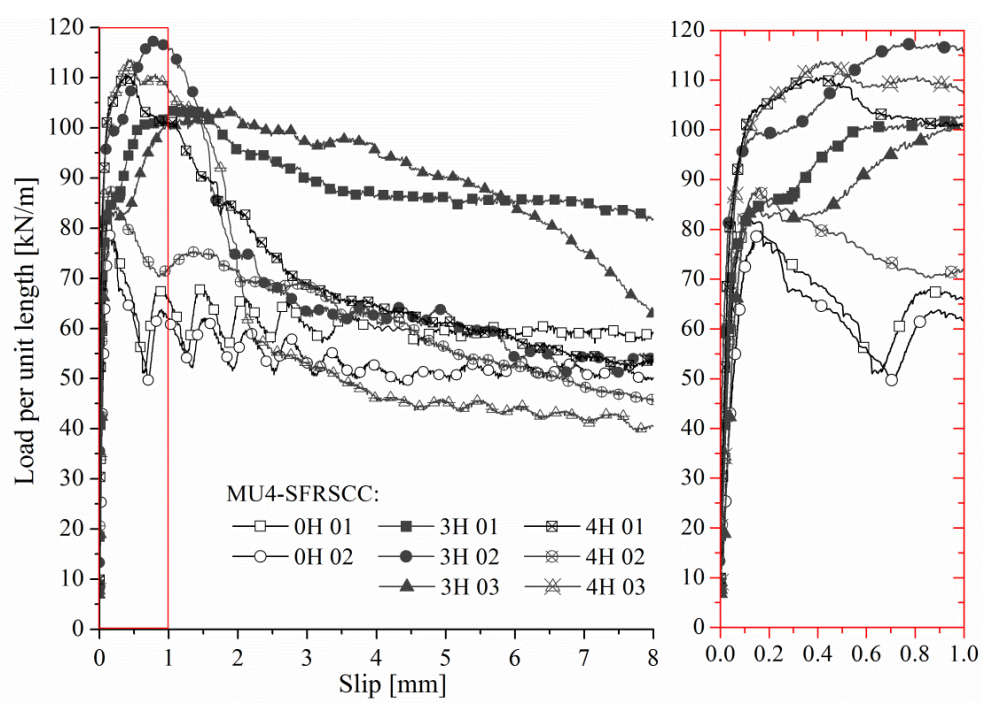

(d)

Figure 18: Influence of the number of holes in the connector on the pull-out load versus slip relationship: (a) CSM-

$$
\text { SCC; (b) CSM-SFRSCC; (c) MU4-SCC and (d) MU4-SFRSCC. }
$$

\subsection{Discussion}

From the above mentioned figures it can be noted that the curves were all characterized by an initial stiff branch ( $K_{\text {tr.i }}$ ranging from 78.8 to $193.3 \mathrm{kN} / \mathrm{mm} / \mathrm{m}$ ), up to the cracking load ( $Q_{t r . c r}$ ), that ranged from 58.1 to $88.8 \mathrm{kN} / \mathrm{m}$. The corresponding slip ( $s_{t r . c r}$ ) ranged from 0.05 to $0.18 \mathrm{~mm}$. After this threshold, the response of the specimens significantly diverged from each other depending on the connection type (i.e.: concrete type, GFRP type, and number of holes). In all the connection types, the dispersion of results becomes higher after concrete crack initiation. For a better understanding of the effect of the studied variables on the pull-out load versus slip response, energy absorption indices were computed. Assuming a generic designation of $\eta_{j}$ for this index, it was obtained through calculation of the area below the corresponding average load-slip curve up to the slip of reference $j$, given in millimetres. Three energy absorption indices were determined, $\eta_{1}, \eta_{2}$, and $\eta_{5}$, whose values are indicated in Table 14. Index $\eta_{1}$ was established considering that, in perforated specimens with SFRSCC, the maximum load capacity is attained for a slip value that is approximately equal to $1 \mathrm{~mm}$. Index $\eta_{2}$ corresponds to post peak load levels that are always higher than $50 \% P_{\max }$ measured in each test performed (with exception to specimen $3 \mathrm{H}-\mathrm{MU} 4-\mathrm{SCC}$ 01) and index $\eta_{5}$ is calculated by computing a high slip deformation and is here used to assess the energy absorption of the connection. 
From the results presented in Table 13 it can be also concluded that the ultimate loads $\left(Q_{t r . u}\right)$ did not exhibit significant dispersion for the specimens of each group. The average and maximum values of the CoV obtained for the ultimate loads were respectively equal to $11 \%$ and $20 \%$.

\subsubsection{Effect of the steel fibre reinforcement of concrete}

It was observed that the load-slip curves obtained from tests with $3 \mathrm{H}$-SCC connections were affected by a significant level of variability, even for companion specimens. Conversely, specimens with 3H-SFRSCC exhibited a more regular behaviour.

From Figure 16 it can be noticed that the use of steel fibre reinforcement in the concrete only significantly affected the behaviour of the connections constituted by perforated plates (3H-CSM and 3H-MU4). In these cases, the use of SFRSCC has increased the load carrying capacity and, predominantly, the energy absorption capacity of the connections, demonstrated by the higher post-peak load capacity of these specimens when compared to those where SCC was used. The average maximum load carrying capacity of 3H-CSM and 3H-MU4 was $18 \%$ and $16 \%$ higher when using SFRSCC than SCC, respectively. The benefits of using SFRSCC instead SCC were even more notable when comparing the $\eta_{5}$ energy absorption index, since it was $64 \%$ and $84 \%$ higher for $3 \mathrm{H}-\mathrm{CSM}$ and $3 \mathrm{H}-\mathrm{MU} 4$, respectively.

The performance of the connections having steel fibre reinforcement for the concrete can also be examined by comparing the slip corresponding to the ultimate load $\left(s_{\text {tr.u }}\right)$. Again, it was found that the use of SFRSCC led to an increase of $s_{t r . u}$ only in the case of specimens comprising perforated connectors. Tests 3H-CSM-SFRSCC and 3H-MU4-SFRSCC have shown $s_{\text {tr.u }}$ about 3.0 and 5.6 times greater than the corresponding values computed for specimens 3H-CSM-SCC and 3H-MU4-SCC, respectively.

The key role played by the SFRSCC in the PERFOFRP is assured by the fibres that offer resistance to the crack opening, resulting higher shear resistance of the SFRSCC dowels, not only by the direct contribution of the fibres, but also due to the higher aggregate interlock in consequence of the crack width restriction. Consequently, when no concrete dowels exist (GFRP plates without holes), fibres do not assure any positive contribution for the pull-out behaviour (see Figure 16) In general, all the connections comprising PERFOFRP plates presented a hardening stage after crack initiation. The abovementioned favourable effects of fibre reinforcement also justify the longer and stiffer hardening branch observed in the 3H-CSM-SFRSCC and 3H-MU4-SFRSCC specimens, when compared to the corresponding ones with SCC (see Figure 16). In the 3H-CSM-SFRSCC specimens, after crack initiation the load has increased up to rupture in the GFRP connector. Conversely, in the 3H-MU4-SFRSCC specimens the 
concrete fracture capacity was exhausted prior to the bearing strength of the GFRP connector has been attained, leading to the formation of a concrete cone rupture.

In the connections comprising flat GFRP laminates without holes, the maximum load almost coincides with the crack formation in the concrete block, regardless the type of concrete adopted. Thus, since the concrete matrix of SFRSCC and SCC is almost equal (see Table 11), and considering that fibres do not affect the adhesion between the concrete and the GFRP laminate, no beneficial effects are expected from using fibres when the GFRP plates do not have holes.

\subsubsection{Effect of the type of GFRP connector}

The obtained results clearly show that when using PERFOFRP connectors, the larger is the load capacity of the GFRP laminate (MU4), the higher is the load carrying capacity and the more pronounced and stiffer is the hardening stage developed after crack initiation up to peak load (Figure 17a and b). In fact, the average of peak load of $3 \mathrm{H}-$ MU4 was $15 \%$ higher than of the $3 \mathrm{H}-\mathrm{CSM}$.

In general, the connections with MU4 laminates presented a more ductile response, independently of the type of concrete, which can be justified by the nonlinear stress-strain response this GFRP develops (Figure 6b). The average values of $\eta_{1}, \eta_{2}$, and $\eta_{5}$ energy absorption indices of 3H-MU4-SCC specimens were 30\%, $13 \%$ and $15 \%$ larger than of the 3H-CSM-SCC specimens. Similar results were found for specimens produced with SFRSCC. However, particularly in these specimens, the greater increases on energy absorption capacity due to the use of $3 \mathrm{H}-\mathrm{MU} 4$ connectors were noticed for higher slips. In these cases, $\eta_{1}, \eta_{2}$, and $\eta_{5}$ energy absorption indices increased $19 \%$, $15 \%$ and $29 \%$ due to the adoption of MU4 laminates, respectively.

In the case of $\mathrm{OH}$ tests, the maximum load of specimens comprising MU4-SCC and MU4-SFRSCC laminates were $19 \%$ and $39 \%$ greater than the average values obtained for the respective connections produced with CSM laminates. In fact, although both GFRP laminates were produced using the same resin type and manufacturing procedures, the GFRP laminates presented different superficial roughness induced by the use of different types of reinforcement (i.e.: chopped strand mat for CSM laminate, and stitched roving fabric for MU4 laminate). This difference possibly led to a higher friction strength for the MU4 laminate. Furthermore, in comparison to the $0 \mathrm{H}-$ CSM-SFRSCC, the OH-MU4-SFRSCC connections also shown a slightly higher load level in the yielding plateau observed after the concrete cracking .

\subsubsection{Effect of the number of holes on the connector}

It is possible to note in Table 13 that, in general, for a certain type of GFRP laminate and concrete, the holes in the connector led to an increase of the load capacity of the connection. Nonetheless, while this increase was statistically 
insignificant for the connections made with SCC (average increase of $8 \%$ and 5\% for CSM-SCC and MU4-SCC, respectively), it became relevant for the connections produced with SFRSCC. For instance, the use of connectors with 3 holes led to a maximum load $64 \%$ and $34 \%$ higher than the one obtained in the connections $0 \mathrm{H}-\mathrm{CSM}$ and 0H-MU4, respectively. Furthermore, the load capacity of connection $4 \mathrm{H}$ was, in average, $29 \%$ greater than the one of the connection 3H-SFRSCC. The influence of the holes in specimens made with SCC and SFRSCC is easily perceived in Figure 18, where the holes contribute for a substantial increase of maximum load and energy absorption, mainly when made with SFRSCC, due to the contribution of fibre reinforcement, as already reported. In fact, the average values measured for $\eta_{1}, \eta_{2}$, and $\eta_{5}$ energy absorption indices were $80.0,169.5$ and $345.1 \mathrm{~N} \cdot \mathrm{m} / \mathrm{m}$ for $3 \mathrm{H}-\mathrm{CSM}$ specimens and $94.9,194.8$ and $445.2 \mathrm{~N} \cdot \mathrm{m} / \mathrm{m}$ for $3 \mathrm{H}-\mathrm{MU} 4$ specimens. In average, these values were $47 \%$ to $78 \%$ higher than the values obtained in the tests performed with specimens comprising connectors without holes.

However, it is highlighted that even the GFRP connectors without holes demonstrated a relatively high maximum load and post-peak resistance. The typical pull-out load versus slip response of the specimens $0 \mathrm{H}$ was characterized by maintaining a post-peak pseudo-yielding plateau at a relatively high load level up to a slip greater than $8 \mathrm{~mm}$ (exception is made for specimen 0H-CSM-SCC 01). For instance, at a slip of $8 \mathrm{~mm}$ the average load capacity of 0HCSM-SFRSCC and 0H-MU4-SFRSCC connections was 45 and $55 \mathrm{kN} / \mathrm{m}$, respectively. Thus, the experimental results proved that the friction plays an important role in the mechanical behaviour of the GFRP-concrete connections, which should not be disregarded for design purposes.

Finally, when the results presented in Figure $18 \mathrm{~d}$ and Table 7 for $3 \mathrm{H}$ and $4 \mathrm{H}$ specimens are compared, it is noticed that when the number of holes per length of connector increased (i.e.: spacing between holes was reduced), the response of the connection became slightly more ductile up to a slip approximately equal to $1.0 \mathrm{~mm}$, but the response rapidly became more brittle for higher slips. In fact, 4H-MU4-SFRSCC showed an increase of $9.0 \%$ on the average value of $\eta_{1}$ energy absorption index, when compared to the value obtained for 3H-MU4-SFRSCC. Conversely, the average $\eta_{5}$ energy absorption index for $4 \mathrm{H}$-MU4-SFRSCC was $16 \%$ lower than the respective value obtained for 3H-MU4-SFRSCC specimens. It is highlighted that the specimen 4H-MU4-SFRSCC 02 was not considered in this comparison since it exhibited a response significantly dissimilar from those obtained for identical specimens (see Figure 18d). 
Table 7: Results of pull-out tests: energy absorption indices computed up to a slip equal to $1 \mathrm{~mm}\left(\eta_{1}\right), 2 \mathrm{~mm}\left(\eta_{2}\right)$ and $5 \mathrm{~mm}\left(\eta_{5}\right)$.

\begin{tabular}{ccccccc}
\hline & \multicolumn{7}{c}{ Energy absorption indices } \\
Connection & \multicolumn{7}{c}{$\eta_{1}$} & \multicolumn{2}{c}{$\eta_{2}$} & $\eta_{5}$ \\
\cline { 2 - 7 } & Avg. & CoV & Avg. & CoV & Avg. & CoV \\
& {$[\mathrm{N} \cdot \mathrm{m} / \mathrm{m}]$} & {$[\%]$} & {$[\mathrm{N} \cdot \mathrm{m} / \mathrm{m}]$} & {$[\%]$} & {$[\mathrm{N} \cdot \mathrm{m} / \mathrm{m}]$} & {$[\%]$} \\
\hline 3H-CSM-SCC & 63.7 & 21 & 126.42 & 14 & 210.3 & 13 \\
3H-CSM-SFRSCC & 80.0 & 9 & 169.55 & 6 & 345.1 & 11 \\
3H-MU4-SCC & 82.8 & 14 & 142.78 & 8 & 240.8 & 36 \\
3H-MU4-SFRSCC & 94.9 & 11 & 194.83 & 4 & 445.2 & 9 \\
0H-CSM-SCC & 56.3 & 17 & 100.26 & 26 & 216.6 & 27 \\
0H-CSM-SFRSCC & 47.9 & 10 & 95.53 & 7 & 234.9 & 4 \\
0H-MU4-SCC & 67.4 & 28 & 126.11 & 34 & 293.5 & 39 \\
0H-MU4-SFRSCC & 63.9 & 5 & 123.39 & 5 & 294.2 & 8 \\
4H-MU4-SFRSCC* & 103.5 & 2.0 & 197.57 & 3.13 & 375.8 & 8.0 \\
\hline
\end{tabular}

*- results of 4H-MU4-SFRSCC 02 were disregarded.

\section{CONCLUSIONS}

This study summarizes the results of pull-out tests on connections comprising GFRP connectors and selfcompacting concrete. The experimental program consisted on 24 specimens made with two different GFRP laminates (CSM and MU4), two types of concrete (SCC and SFRSCC) and three different geometries for the connector (without holes, with 3 holes and with 4 holes). The main objective of this investigation was to obtain a better understanding of the proposed connections, evaluating the influence of the studied variables on the initial stiffness, load capacity and ductility of connections. The following conclusions can be drawn for connections made with materials and geometry similar to the used in this study:

1. In general, connections made with CSM PERFOFRP connectors had the load carrying capacity limited by the rupture of the connector in the vicinity of the holes. The post testing inspection of the specimens pointed out that three typical failure lines appeared in the connectors that crossed the connector from the hole edge to the connector bottom edge: two inclined about $45^{\circ}$ and one $90^{\circ}$ with the horizontal just below the holes. Nonetheless, one of specimens produced with SCC presented a distinct failure mode by shear in the planes of contact between the concrete and the connector (dowel effect + friction/adhesion), what can indicate that this failure mode happens for a load level not much different of the load that leads to the failure mode associated to the rupture of the connector itself.

2. Premature ruptures of the concrete block were observed in specimens made with MU4 PERFOFRP connectors. In these specimens, the presence of two different failure patterns was observed: (1) rupture by shear along the 
interface surfaces between the connector and the concrete block, where prevails the combined effect of shear in the concrete dowels and in the net contact area by friction/adhesion; (2) concrete cone failure, with the formation of a ruptured cone with the apex located immediately below the holes and making and angle with the horizontal approximately equal to $47^{\circ}$.

3. The load versus slip responses of all tested PERFOFRP-concrete connections were characterized by an initial stiff branch up to the cracking load. After this threshold, the response of the specimens significantly diverged from each other depending on the connection type.

4. The use of steel fibre reinforcement in the concrete significantly affected the behaviour of connections that comprised PERFOFRP connectors, increasing the load carrying capacity and the energy absorption capacity of the connections. The load carrying capacity of $3 \mathrm{H}$ connections increased $17 \%$ in average. For the specimens with $\mathrm{OH}$, the use steel fibres did not significantly affect the friction/adhesion between the connector and the concrete.

5. The connections with MU4 laminates presented a more ductile response, independently of the type of concrete.

6. In average, the ultimate load capacities of connections made SFRSCC and 3 holes increased $49 \%$ when compared with connections made with the same concrete and GFRP laminates without holes.

\section{ACKNOWLEDGEMENTS}

This work is part of the research project QREN number 5387, LEGOUSE, involving the companies Mota-Engil, CiviTest, the ISISE/University of Minho and PIEP. The first author would like to thank the financial support provided by PAIP/UNILA. The third author wish to acknowledge the grant SFRH/BSAB/114302/2016 provided by FCT. 


\section{Table captions}

Table 8: Composites lay-ups and thicknesses.

Table 9: Total amount of glass fibre per composite.

Table 10: Ultimate tensile stress $\left(\sigma_{\text {pt.u }}\right)$, strain $\left(\varepsilon_{\text {pt.u }}\right)$, elastic limit stress $\left(\sigma_{\text {pt.el }}\right)$, strain $\left(\varepsilon_{\text {pt.el }}\right)$ and tensile modulus of elasticity $\left(\mathrm{E}_{\mathrm{pt}}\right)$ of composites.

Table 11: Compositions of SFRSCC and SCC per $\mathrm{m}^{3}$ of concrete.

Table 12: Maximum engineering normal strains in the region of the GFRP connectors between the concrete block and the grips.

Table 13: Results of pull-out tests: ultimate load $\left(Q_{u}\right)$, slip corresponding to the ultimate load $\left(s_{u}\right)$, cracking load $\left(Q_{c r}\right)$, slip corresponding to the cracking load $\left(s_{c r}\right)$ and initial stiffness $\left(K_{i}\right)$.

Table 14: Results of pull-out tests: energy absorption indices computed up to a slip equal to $1 \mathrm{~mm}\left(\eta_{1}\right), 2 \mathrm{~mm}\left(\eta_{2}\right)$ and $5 \mathrm{~mm}\left(\eta_{5}\right)$. 


\section{Figure captions}

Figure 1: Sandwich panel comprising GFRP connectors.

Figure 2: Bearing loads acting on the connectors: a) longitudinal shear (e.g.; during transporting); b) transversal shear (e.g.; during stripping and transporting).

Figure 3: Failure mechanisms likely to occur when the connections are subjected to transversal shear. On SFRSCC: a) shear of the SFRSCC dowels; b) concrete cone rupture and c) crushing. On GFRP connector: d) rupture of the GFRP below the SFRSCC dowels; e) rupture of the GFRP between the SFRSCC dowels and f) rupture of the GFRP on the free section.

Figure 4: Main load transfer mechanisms acting on the connectors due to loads applied transversally to the concrete layer: a) SFRSCC dowel effect (including the fibre reinforcement mechanisms); b) friction/adherence resistance between GFRP and SFRSCC.

Figure 5: Schematic representation of used materials: (a) CSM; (b) BIA; (c) MU2; (d) MU4.

Figure 6: Experimental stress versus strain relationship for the direct tensile behaviour of the GFRPs in the $0^{\circ}$ direction (along $x$-axis according to the global axis): (a) CSM; (b) MU4.

Figure 7: Layout of specimens: (a) front view and (b) lateral view of $0 \mathrm{H}$ connector; (c) front view of PERFOFRP connectors; (d) lateral view of $3 \mathrm{H}$ connector; (e) lateral view of $4 \mathrm{H}$ connector (dimensions in millimeter).

Figure 8: Production of pull-out specimens: (a) overall view of formwork; (b) pouring of 3H-MU4-SCC specimen.

Figure 9: Experimental program: nomenclature of specimens and overall explanation.

Figure 10: Pull-out test setup: (a) overall view. (b) Schematic representation of layout of LVDTs: (c) front view, (d) left view, (e) right view (dimensions in millimeter).

Figure 11: Detail of typical vertical cracking of concrete blocks: (a) 3H-CSM-SFRSCC and (b) 3H-CSM-SCC.

Figure 12: Representative aspect of GFRP connectors after failure: (a) 3H-CSM-SCC 02; (b) 3H-CSM-SFRSCC 01; (c) 3H-MU4-SCC 01; (d) 3H-MU4-SFRSCC 02; (e) 0H-CSM-SFRSCC 01; (f) 4H-MU4-SFRSCC 01.

Figure 13: Detail of typical failure modes of specimens comprising CSM laminate with holes: (a) 3H-CSMSFRSCC; (b) 3H-CSM-SCC.

Figure 14: Detail of typical failure modes of specimens comprising MU4 laminate with holes: (a) 3H-MU4-SCC; (b) 4H-MU4-SFRSCC.

Figure 15: Representative pull-out load versus slip relationship, with identification of the observed failure modes: (a) 3H-CSM-SFRSCC; (b) 3H-MU4-SFRSCC and (c) 0H-MU4-SFRSCC.

Figure 16: Influence of the concrete type on the pull-out load versus slip relationship: (a) 3H-CSM; (b) 3H-MU4; (c) $0 \mathrm{H}-\mathrm{CSM}$ and (d) $0 \mathrm{H}-\mathrm{MU} 4$.

Figure 17: Influence of the GFRP laminate on the pull-out load versus slip relationship: (a) 3H-SCC; (b) $3 \mathrm{H}-$ SFRSCC; (c) 0H-SCC and (d) OH-SFRSCC.

Figure 18: Influence of the number of holes in the connector on the pull-out load versus slip relationship: (a) CSMSCC; (b) CSM-SFRSCC; (c) MU4-SCC and (d) MU4-SFRSCC. 


\section{REFERENCES}

[1] D. Salmon, A. Einea, Partially Composite Sandwich Panel Deflections, Journal of Structural Engineering 121(4) (1995) 778-783.

[2] D.C. Salmon, A. Einea, M.K. Tadros, T.D. Culp, Full scale testing of precast concrete sandwich panels, ACI Structural Journal 94(4) (1997) 354-362.

[3] A. Benayoune, A.A.A. Samad, D.N. Trikha, A.A. Abang Ali, A.A. Ashrabov, Structural behaviour of eccentrically loaded precast sandwich panels, Construction and Building Materials 20(9) (2006) 713-724.

[4] A. Benayoune, A.A.A. Samad, A.A. Abang Ali, D.N. Trikha, Response of pre-cast reinforced composite sandwich panels to axial loading, Construction and Building Materials 21(3) (2007) 677-685.

[5] A. Benayoune, A.A.A. Samad, D.N. Trikha, A.A.A. Ali, S.H.M. Ellinna, Flexural behaviour of pre-cast concrete sandwich composite panel - Experimental and theoretical investigations, Journal of Construction and Building Materials 22(4) (2008) 580-592.

[6] F. Gara, L. Ragni, D. Roia, L. Dezi, Experimental tests and numerical modelling of wall sandwich panels, Engineering Structures 37(0) (2012) 193-204.

[7] T.D. Bush, Z. Wu, Flexural Analysis of Prestressed Concrete Sandwich Panels with Truss Connectors, Precast/Prestressed Concrete Institute Journal 43(5) (1998) 76-86.

[8] PCI Committee on Precast Sandwich Wall Panels, State-of-the-art of Precast/Prestressed Sandwich Wall Panels, Precast/Prestressed Concrete Institute Journal 56(2) (2011) 131-175.

[9] R. Lameiras, J. Barros, M. Azenha, I.B. Valente, Development of sandwich panels combining fibre reinforced concrete layers and fibre reinforced polymer connectors. Part I: conception and pull-out tests, Composite Structures 105(November 2013) (2013) 446-459.

[10] R. Lameiras, J. Barros, M. Azenha, I.B. Valente, Development of sandwich panels combining fibre reinforced concrete layers and fibre reinforced polymer connectors. Part II: Evaluation of mechanical behaviour, Composite Structures 105(0) (2013) 460-470.

[11] W. Zellner, Recent designs of composite bridges and a new type of shear connectors, IABSE/ASCE Engineering Foundation Conference on Composite Construction, Henniker NH, 1987, pp. 240-252.

[12] F. Leonhardt, W. Andrä, H.P. Andrä, W. Harre, New advantageous shear connection for composite structures with high fatigue strength (Neues vorteilhaftes verbundmittel für stahlverbundtragwerke mit höher dauerfestigkeit), Beton und Stahlbetonbau 62(12) (1987) 325331.

[13] E.C. Oguejiofor, M.U. Hosain, Behaviour of perfobond rib shear connectors in composite beams: full-size tests, Canadian Journal of Civil Engineering 19(2) (1992) 224-235.

[14] J.C. Galjaard, J.C. Walraven, Static tests on various types of shear connectors for composite structures, International symposium on connections between steel and concrete, 2001, pp. 13131322.

[15] J. Machacek, J. Studnicka, Perforated shear connectors, Steel \& Composite structures: an international journal 2(1) (2002) 51-66.

[16] P.C.G. da S. Vellasco, S.A.L. de Andrade, L.T.S. Ferreira, L.R.O. de Lima, Semi-rigid composite frames with perfobond and T-rib connectors Part 1: Full scale tests, Journal of Constructional Steel Research 63(2) (2007) 263-279.

[17] I.B. Valente, P.J.S. Cruz, Experimental analysis of shear connection between steel and lightweight concrete, Journal of Constructional Steel Research 65(10-11) (2009) 1954-1963.

[18] J.-H. Ahn, C.-G. Lee, J.-H. Won, S.-H. Kim, Shear resistance of the perfobond-rib shear connector depending on concrete strength and rib arrangement, Journal of Constructional Steel Research 66(10) (2010) 1295-1307. 
[19] K. Cho, S. Park, S. Kim, J.-R. Cho, B.-S. Kim, Shear connection system and performance evaluation of FRP-concrete composite deck, KSCE Journal of Civil Engineering 14(6) (2010) 855-865.

[20] E.C. Oguejiofor, M.U. Hosain, Numerical analysis of push-out specimens with perfobond rib connectors, Computers \& Structures 62(4) (1997) 617-624.

[21] S.B. Medberry, B.M. Shahrooz, Perfobond shear connector for composite construction, Engineering Journal of American Institute of Steel Construction (AISC) 39(1) (2002) 2-12.

[22] E.C. Oguejiofor, M.U. Hosain, A parametric study of perfobond rib shear connectors, Canadian Journal of Civil Engineering 21(4) (1994) 614-625.

[23] G.S. Verissimo, Development of a shear connector plate gear for composite structures of steel and concrete and study their behavior, Universidade Federal de Minas Gerais, Belo Horizonte, 2007.

[24] J.d.C. Vianna, L.F. Costa-Neves, P.C.G. da S. Vellasco, S.A.L. de Andrade, Experimental assessment of Perfobond and T-Perfobond shear connectors' structural response, Journal of Constructional Steel Research 65(2) (2009) 408-421.

[25] Ashland, Aropol unsaturated polyester resins: Aropol S 604 TC low stryrene content resin Ashland, 2009.

[26] ASTM, D2584 - 11: Standard Test Method for Ignition Loss of Cured Reinforced Resins, American Society for Testing and Materials (ASTM), Philadelphia, PA, 2011.

[27] ASTM Standard D 3039/D 3039M, Tensile Properties of Polymer Matrix Composite Materials, ASTM International, West Conshohocken, PA, 2008.

[28] ASTM D 5379-93, Test method for shear properties of composite materials by the Vnotched beam method, American Society for Testing and Materials, Philadelphia, PA, 1993.

[29] R.M. Lameiras, J. Barros, I.B. Valente, J. Xavier, M. Azenha, Pull-out behaviour of glassfibre reinforced polymer perforated plate connectors embedded in concrete. Part II: Prediction of load carrying capacity, In this Journal In this Volume(In this Issue) (2015).

[30] E. Pereira, J. Barros, A. Ribeiro, A. Camões, Post-cracking behaviour of selfcompacting steel fibre reinforced concrete, 6th International RILEM Symposium on Fibre Reinforced Concrete - BEFIB 2004, Varenna, 2004.

[31] V.M. Cunha, J.A. Barros, J.M. Sena-Cruz, Pullout behavior of steel fibers in selfcompacting concrete, Journal of Materials in Civil Engineering 22(1) (2009) 1-9.

[32] V.M.C.F. Cunha, J.A.O. Barros, J.M. Sena-Cruz, An integrated approach for modelling the tensile behaviour of steel fibre reinforced self-compacting concrete, Cement and Concrete Research 41(1) (2011) 64-76.

[33] EFNARC, The European guidelines for self-compacting concrete, 2005.

[34] CEN, EN 12390-3. Testing hardened concrete - Part 3: compressive strength of specimens, European Committee for Standardization (CEN), Lisbon, 2009, p. 21.

[35] LNEC E397, Betões. Determinação do módulo de elasticidade em compressão (technical report), Laboratório Nacional de Engenharia Civil (LNEC), Lisbon, 1993.

[36] RILEM TC 14-CPC, Modulus of elasticity of concrete in compression (CPC8), Materials and Structures 6(30) (1975) 25-27.

[37] ASTM C469, Standard test method for static modulus of elasticity and poisson's ratio of concrete in compression, Annual Book of ASTM Standards (04.02), American Society of Testing Materials (ASTM), West Conshohocken, Pennsylvania, 1994.

[38] Japan Society of Civil Engineers, JSCE-SF4: Method of tests for flexural strength and flexural toughness of steel fiber reinforced concrete. Part III-2 Method of tests for steel fiber reinforced concrete, Concrete library of JSCE, 1984, pp. 58-61. 